\title{
A regional view of an impending invasion: western corn rootworm development in Northern Germany
}

\author{
Dissertation \\ zur Erlangung des Doktorgrades \\ der Fakultät für Agrarwissenschaften \\ der Georg-August-Universität Göttingen
}

vorgelegt von

Anne Wilstermann

geboren in Itzehoe

Göttingen, März 2012 


\section{7}

1. Referent: Prof. Dr. Stefan Vidal

2. Korreferent: Prof. Dr. Teja Tscharntke

Tag der mündlichen Prüfung: 31. Mai 2012 


\section{Table of contents}

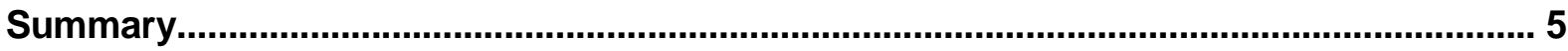

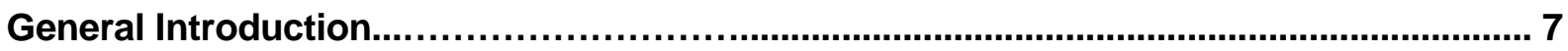

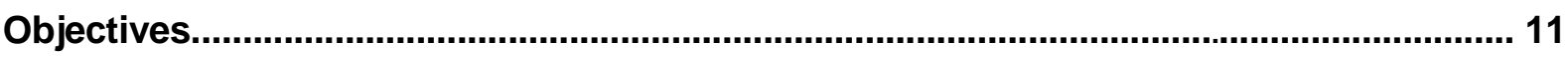

Chapter 1: Does sowing date influence western corn rootworm (Diabrotica virgifera virgifera LeConte) development in Northern Germany under today's temperature regime

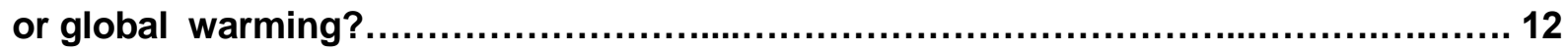

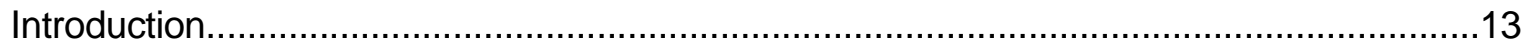

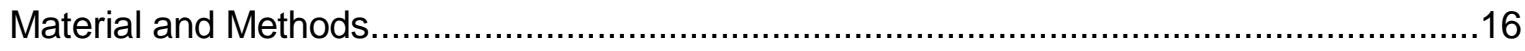

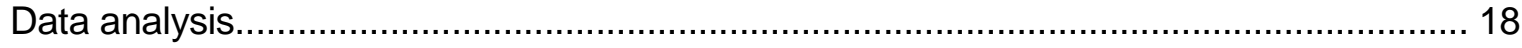

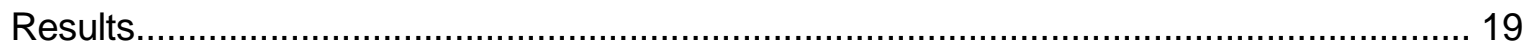

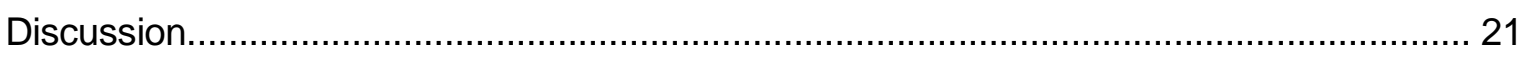

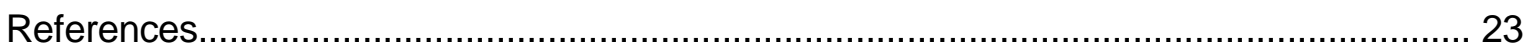

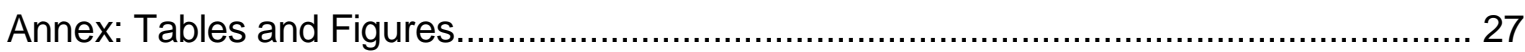

Chapter 2: Western corn rootworm (Diabrotica virgifera virgifera LeConte) development under constant and varying temperature regimes........................................... 31

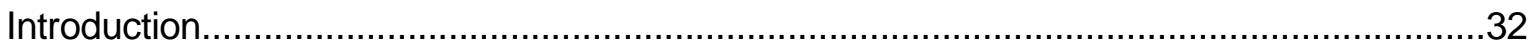

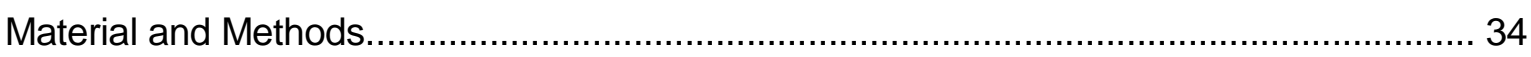

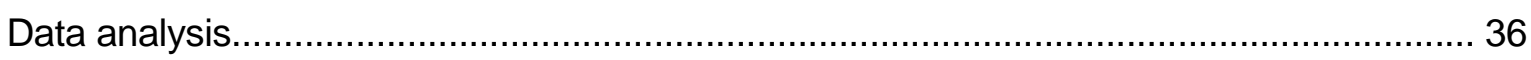

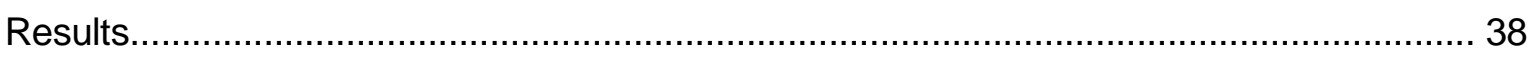

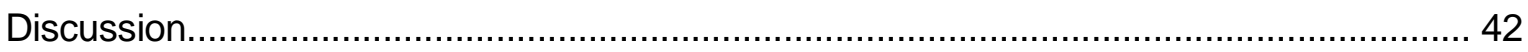

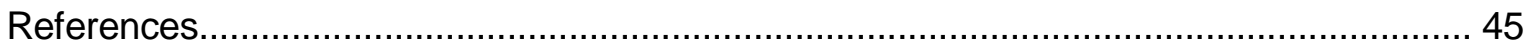

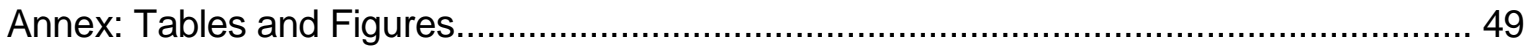

Chapter 3: Development of two different European western corn rootworm (Diabrotica virgifera virgifera LeConte) populations compared with the US non-diapausing laboratory population under a Northern German temperature regime..................... 56

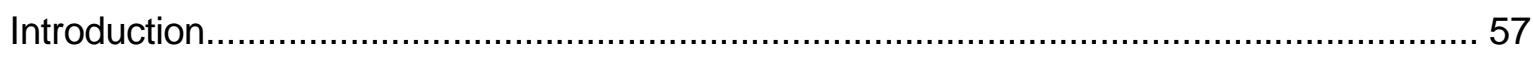

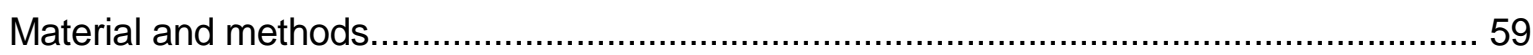

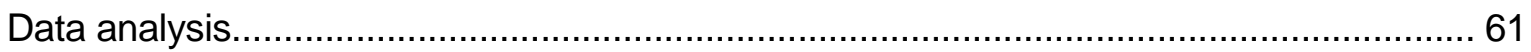

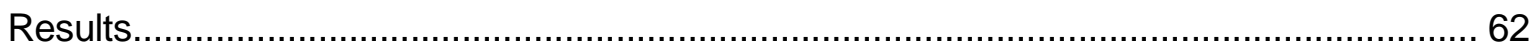

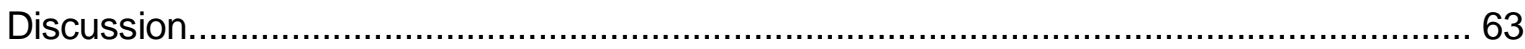




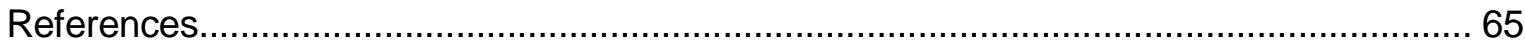

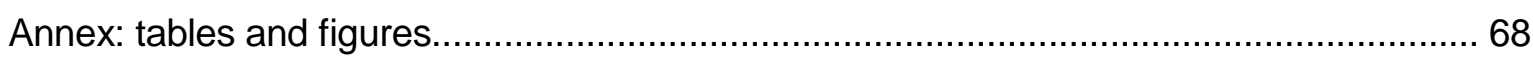

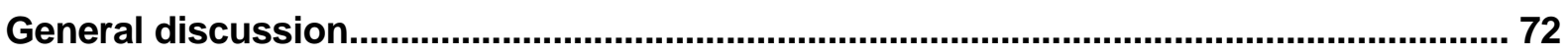

References of general introduction and general discussion.......................................... 75

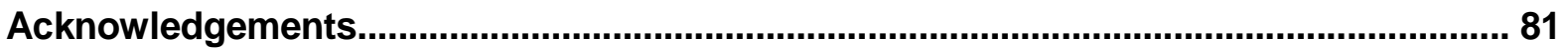

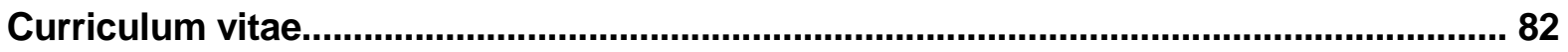

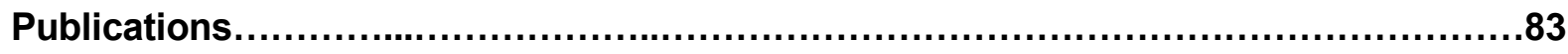

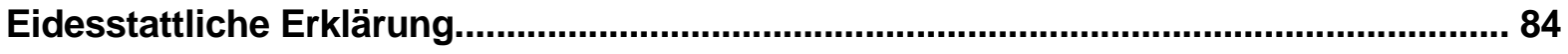




\section{Summary}

We examined the invasive maize pest western corn rootworm (Diabrotica virgifera virgifera LeConte; Chrysomelidae, Galerucinae; WCR) under Northern German temperature regimes. The experiments were conducted under quarantine conditions in climatic cabinets. Aim of the study was an improved knowledge of western corn rootworm biological key data under regional conditions which were necessary for an adequate integrated pest management strategy.

1. The influence of a delayed sowing date under recent temperature regime and a warmed temperature regime was studied:

- The temperature regime did not influence hatching rates.

- The time of mean hatch was accelerated from JD 195 under the temperature regime of today to JD 177 under the warmed regime.

- Sowing date did not affect development under the temperature regime of today.

- Under the warmed regime larval development was retarded at the late sown plants.

2. We evaluated the effects of varying day-night $\left(4^{\circ} \mathrm{C}\right.$ and $6^{\circ} \mathrm{C}$ difference) temperature regimes compared to the equivalent constant temperature regime on hatch, development and recovery of WCR larvae:

- Varying day-night temperatures resulted in earlier larval hatch and accelerated larval development.

- This effect was fortified by a temperature difference of $6^{\circ} \mathrm{C}$ compared to the $4^{\circ} \mathrm{C}$-difference regime.

- Hatching rate and larval recovery were not affected by the different temperature regimes. 
3. We compared two different European western corn rootworm field populations from Serbia and Hungary with the US non-diapausing laboratory population:

- There was a slight higher thermal requirement for hatching of the Hungarian and Serbian populations compared to the laboratory population.

- The Hungarian population showed highest thermal requirements for hatch.

There was a strong positive correlation between plant height and larval performance respectively, plant height and larval recovery in all experiments. 


\section{General Introduction}

“Nothing endures but change." - Heraclitus (535 BC - 475 BC)

It is a basic necessity for scientists and farmers to face new circumstances and adapt to new challenges like climate change and invasive species, which are considered to be gravely threads of biodiversity, ecosystem functions and agriculture (Pimentel, Zuniga, \& Morrison 2005; Vidal, Kuhlmann, \& Edwards 2005; Ziska et al. 2010). It is challenging to make reliable predictions about climate change, because of technical and political uncertainties which caused different gas emission scenarios and the statistical bias of different models (Allen et al. 2000; Stainforth et al. 2005). Climate change has various direct and indirect effects on ecosystems and organisms, hence also on the relationship of organisms to each other (Dewar \& Watt 1992; Buse \& Good 1996; Cannon 1998; Stange \& Ayres 2010) by elevated atmospheric $\mathrm{CO}_{2}$-concentration (Johnson et al. 2011), changed precipitation and a general global warming by $0.6^{\circ} \mathrm{C}$ in the last 100 years (Walther et al. 2002). A close examination of climate change impact on species interaction like plant-pollinator or plant-pest synchrony is necessary (Tylianakis et al. 2008). A warming of the global mean surface by a temperature of $1.4-5.8^{\circ} \mathrm{C}$ is assumed from the year 1990 till 2100 (Houghton et al. 2001) or $1.1-6.4^{\circ} \mathrm{C}$ till the end of 21 st century (IPCC \& I 2007). Climate change is supposed to lead to a higher productivity of temperate agriculture through longer growing seasons, but also to the worsening of many pests (Porter, Parry, \& Carter 1991; Cannon 1998). Even if climate change is a global phenomenon, adaptations to its impacts have to proceed on a low spatial scale (Gregory et al. 2009; Rannow et al. 2010). Climatic conditions are the most important determinants of the distributions and abundance of poikilothermic species, therefore climate change leads to wide range shifts of several species (Walther et al. 2002; Parmesan \& Yohe 2003; Thomas et al. 2004). Also the establishment and success of invasive species are likely to be affected by climate change (Mooney \& Hobbs 2000; Ziska et al. 2010). An invasive species is defined as "a non-native species whose introduction does or is likely to cause economic or environmental harm or harm to human, animal, or plant health" (National Invasive Species Council 2006). Invasive crop pests cause high economic damage by yield loss and control costs: alone in the US economic losses by invasive pests sum up to almost $\$ 120$ billion per year 
(Pimentel et al. 2008). Most successful invaders have a high abundance and big native distribution range (Williamson \& Fitter 1996).

The western corn rootworm (Diabrotica virgifera virgifera LeConte, Galerucinae, Chrysomelidae; WCR) is a maize pest native to Central America (Melhus, Painter, \& Smith 1954) which has spread over North America from the mid of $19^{\text {th }}$ century till today (Gray et al. 2009). In the late seventies or early eighties of the 20th century it was accidentally introduced from North America into Serbia (Szalai et al. 2010), where it was detected in 1992 near the Belgrade airport (Gray et al. 2009). In 2010 this quarantine pest has already been reported from more than 20 European countries (EPPO 2011) (Figure 1). When the WCR has established in most maize growing regions in Europe, damage costs of more than 470 million Euros per year are predicted (Wesseler \& Fall 2010). The distribution situation of the year 2011 is pictured in Figure 1.

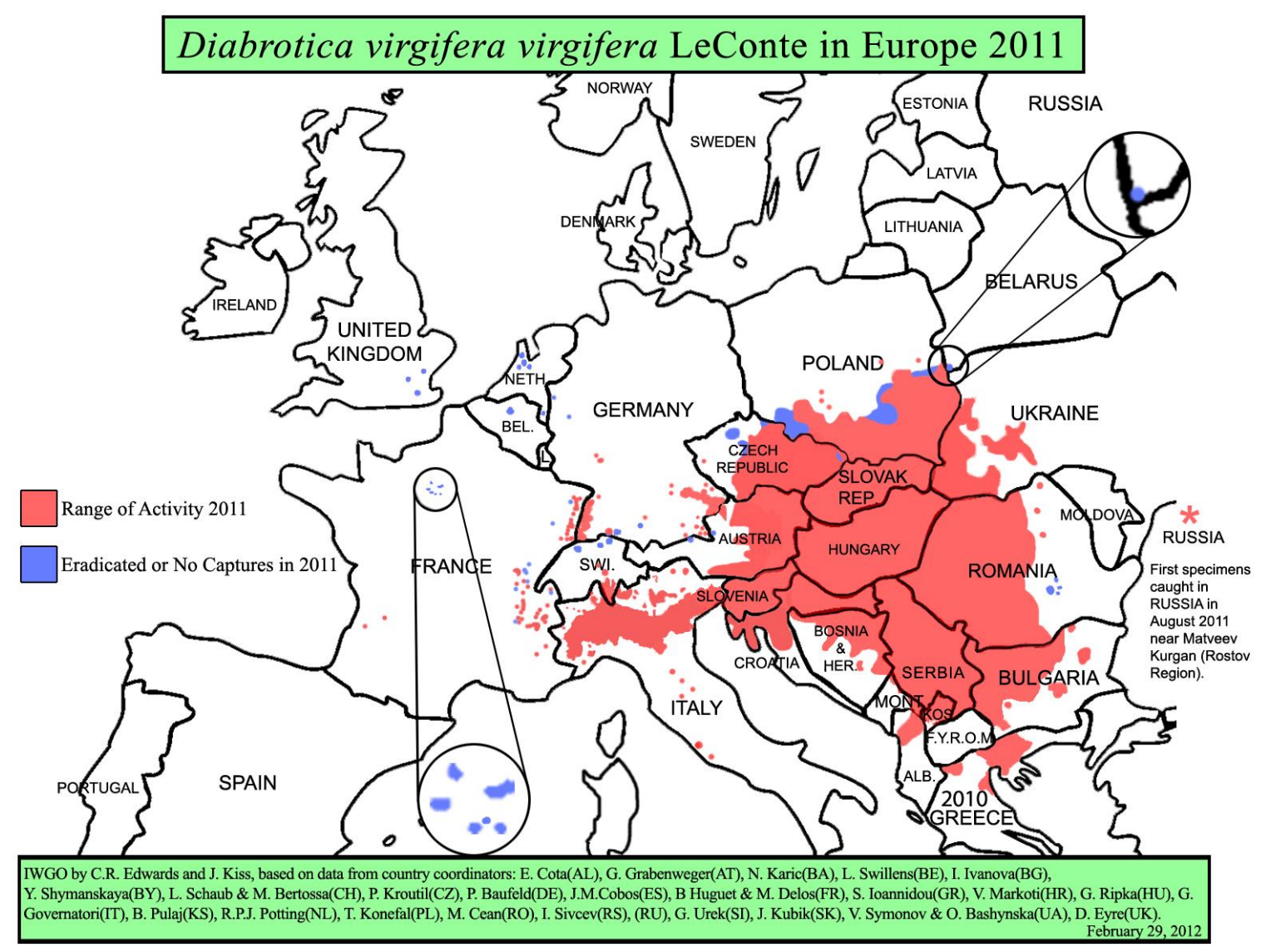

Figure 1: western corn rootworm distribution in Europe 2011 monitored with pheromone traps (Edwards \& Kiss 2012). 
The first WCR was detected in 2007 in Germany (Gray et al. 2009), despite extensive containment and eradication measures WCR could establish in Southern Germany and still spread northward. WCR future spread and distribution is not assumed to be limited by the German climate (Baufeld, Enzian, \& Motte 1996), but highly influenced by cropping practices. Western corn rootworm females lay their eggs in autumn mainly in maize fields. The eggs overwinter in the soil in diapause which ends in spring at a threshold temperature of $11^{\circ} \mathrm{C}$ (Wilde 1971). Larvae hatch and infest the host plant roots. Most damage is caused by the root feeding of the three larval stages, which upsets nutrient and water uptake and lowers plant stability (Kahler et al. 1985; Oleson et al. 2005; Riedell 1990; Spike \& Tollefson 1989). The most effective management strategy of the WCR is crop rotation (Spencer et al. 2009), even though the larvae are also able to survive on some alternative host plants (Moeser \& Vidal 2004). Figure 2 shows the areas in Germany with a high percentage of continuous maize in crop rotation, these areas have a high risk of permanent establishment and heavy infestations by the WCR (Schaafsma, Baufeld, \& Ellis 1999).

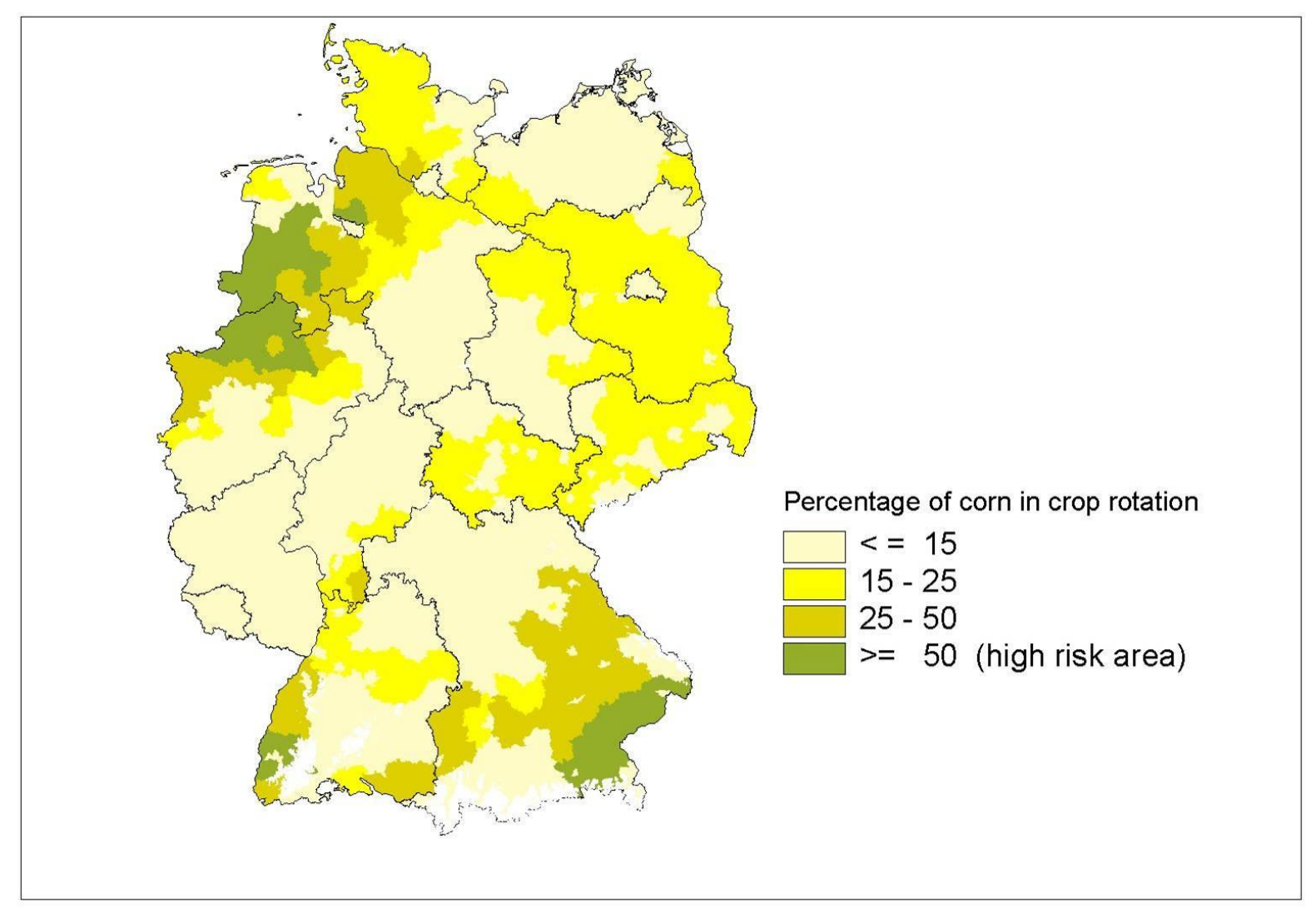

Figure 2: percentage of maize in the crop rotation in Germany (Schaafsma, Baufeld, \& Ellis 1999) 
WCR shows a high adaptability to pest management strategies, with one population even adapting to crop rotation when maize is planted after soybeans (Levine et al. 2002) or also showing locally evolved resistance to some insecticides (Meinke et al. 1998; Wright et al. 2000) and one cultivar of Bt maize (Gassmann et al. 2011). For this reason an integrated pest management (IPM) strategy against WCR is needed for prospective sustainable maize cropping in Europe (Gray 2010). Effective IPM strategies for agricultural pests need the detailed knowledge of key data from the ecology and biology of pest species, the host and their interaction (Awmack \& Leather 2002; Spencer et al. 2009). Development of poikilotherms like insects and plants is highly temperature dependent (Beck 1983; Behrens et al. 1983; Liu, Zhang, \& Zhu 1995; Bergant \& Trdan 2006). There are species specific requirements for the amount of thermal energy (thermal constant) needed to accomplish different life stages (Damos \& Savopoulou-Soultani 2012). Day-degrees and the thermal thresholds for development are reliable predictors for key data of poikilotherms like dormancy, insect egg hatch, budburst or plant flowering at constant temperatures. In most terrestric habitats varying day/night temperatures are pronounced and constant temperature regimes, typically set-up in laboratory tests, are thus unlikely to mimic the influences the insects are exposed to under field conditions (Howe 1967). The WCR itself has adapted well to his invaded areas. The threshold of development and needed thermal energy for development differs slightly between geographical separated populations (Wilde 1971; Wilde et al. 1972; Chiang 1973; Ruppel, Russell, \& Jennings 1978; Fisher 1989; Levine, Oloumi-Sadeghi, \& Ellis 1992; Davis, Brenes, \& Allee 1996). Genetic differences between the US populations are low, but positive correlated with geographic distance (Kim \& Sappington 2005). In consideration of the at least 5 independent WCR introductions from North America into Europe (Ciosi et al. 2008) it is very likely that European populations were introduced from different source populations with different thermal requirements and adaptations to management measures (Sappington, Siegfried, \& Guillemaud 2006). 


\section{Objectives}

In our study we analysed the western corn rootworm hatch, larval development and recovery under a Northern German temperature regime.

1. Does sowing date influence western corn rootworm development in Northern Germany under today's temperature regime or global warming?

In this experiment the influence of a moderate delay of the maize sowing date under simulated a) temperature regime of today and b) a changed temperature regime with elevated spring and summer temperatures by $2^{\circ} \mathrm{C}$ in Northern Germany was examined. Specifically addressing the questions:

- Does a delaying sowing date under the temperature regime of today influence WCR development and recovery by disrupting host-pest synchrony?

- Is this influence enhanced under the elevated temperature regime by the combined effects of an earlier start of development and a delayed sowing of maize?

2. Western corn rootworm development under constant and varying temperature regimes

We analysed the effect of varying day-night temperatures with $4^{\circ} \mathrm{C}$ difference, respectively $6^{\circ} \mathrm{C}$ difference compared with the adequate mean temperature:

- Do varying ambient temperatures influence WCR development and recovery in comparison to the adequate mean temperature?

3. Development of two different European western corn rootworm populations compared with the US non-diapausing laboratory population under a Northern German temperature regime

We tested for developmental differences between the US non-diapausing laboratory population and two European field populations from Serbia and Hungary:

- Are there differences between the populations with regard to their hatching patterns, development and recovery?

- Is the US-non diapausing laboratory population an adequate organism to study WCR development in Europe? 
Does sowing date influence western corn rootworm (Diabrotica virgifera virgifera LeConte) development in Northern Germany under today's temperature regime or global warming?

\section{Abstract}

Adaptation to climate change and invasive species is an essential challenge for research. We tested the influence of two different maize sowing dates on JD 121 and JD 135 under two temperature regimes on the development and recovery of the invasive maize pest western corn rootworm in climate cabinets. We used a recent temperature regime from Northern Germany and the "climate change" regime which was increased by $2^{\circ} \mathrm{C}$ to simulate an earlier start of egg development in spring. The experiment started with the threshold temperature of western corn rootworm development at $11^{\circ} \mathrm{C}$, which was reached at JD 121 at the first sowing date for the temperature regime of today and at JD 107 under the change regime. We assumed an effect on plant-pest synchrony by delayed sowing and a fortification of this effect under the increased temperature regime. Larval hatch did not differ between the temperature regimes with regard to the temperature sum necessary for hatch and the hatching rates. Due to the earlier start of egg development under the change regime the mean hatch occurred earlier (JD 177) compared to today's regime (JD 195). Under the recent temperature regime a delay of the sowing date did not affect larval development, but under the change regime larval development was retarded at the late sown plants. We assumed that early hatched larvae died by starvation on these plants. There was a strong positive correlation between plant height and larval performance and larval recovery in our experiment. 


\section{Introduction}

The world around us changes. Scientists and farmers have to face new circumstances like climate change and invasive species (Ziska et al. 2010). On one hand a higher productivity of temperate agriculture by longer growing seasons is assumed, on the other hand the prediction of the worsening of many pests by climate change (Cannon 1998). Climatic conditions are the most important determinants of the distribution and abundance of poikilothermic species (Walther et al. 2002). In agricultural ecosystems, weather affects crop yield and quality as well as the dynamics of pests and their regulation by natural enemies. Today, there is little doubt that the climate changes, but it is challenging to make reliable predictions because of technical and political uncertainties which resulted in different gas emission scenarios and the statistical bias of different models (Stainforth et al. 2005). Even if climate change is a global phenomenon, adaptations to its impacts have to proceed on a small spatial scale (Gregory et al. 2009; Rannow et al. 2010).

But although if it is not known in detail how the climate will change, we can investigate how discrete factors would affect key data of the biology of organisms to give the possibility to model the influence when these factors changes. Effective integrated management strategies for agricultural pests are predicated on the detailed knowledge of key data from the pest species, the host and their interaction (Awmack \& Leather 2002). An increase in temperature would lead to complex changes in species specific insect life-history traits and phenology (Deutsch et al. 2008; Musolin et al. 2010). While some studies predict distribution shifts for species like for Ostrinia nubilalis (Porter et al. 1991), an earlier pest activity by global warming such as for the cabbage root fly Delia radicum (Collier et al. 1991), or the faster development of the spittlebug (Neophilaenus lineatus) triggered by an earlier hatch (Whittaker \& Tribe 1996), other studies deal with indirect climate effects by the interaction with the host-plant (Buse \& Good 1996; Cannon 1998; Dewar \& Watt 1992; Parmesan 2007; Stange \& Ayres 2010). Under natural conditions synchrony of plant and pest development would be preserved when elevated temperatures proceed similarly for both. The expected temperature effect on larval survival of the winter moth (Operophtera brumata) (Dewar \& Watt 1992) could not be verified in experiments, as there was no influence of elevated temperatures on the synchrony of the winter moth and budburst in oaks (Buse \& Good 1996). In agricultural systems 
the synchrony of host plant and pest can be disrupted by human determination of the start of plant growing.

Subject of our study were the immature stages of western corn rootworm (Diabrotica virgifera virgifera LeConte, Galerucinae, Chrysomelidae; WCR). WCR is an invasive quarantine maize pest native to Central America (Melhus et al. 1954). In the late seventies or early eighties of the 20th century it was accidentally introduced from North America to Serbia (Szalai et al. 2010), where it was detected in 1992 near the Belgrade airport (Gray et al. 2009). In 2010 this pest has already been reported from more than 20 European countries (EPPO 2011). During the last 20 years at least 5 independent introductions into Europe took place (Ciosi et al. 2008). In case of an establishment of this pest in most maize growing regions in Europe damage costs are expected to sum up to more than 470 million Euro per year (Wesseler \& Fall 2010).

Western corn rootworm females lay their eggs in the maize field in autumn, rarely in other crops (Shaw et al. 1978). The eggs overwinter in the soil in diapause which ends in spring at a threshold temperature of $11^{\circ} \mathrm{C}$ (Wilde 1971). Larvae hatch and infest the host plant roots. Most damage is caused by the root feeding of larvae, which disrupts nutrient and water uptake and lowers plant stability (Kahler et al. 1985; Riedell 1990).

Even if WCR distribution is not assumed to be limited by German climate (Aragón \& Lobo 2012; Baufeld et al. 1996), effects of climate change on WCR development, survival and damage potential are expected by more favourable conditions. In this study we analysed the combined effects of an earlier start of development and a delayed sowing on the synchrony of WCR development and host phenology. In the past field studies in North America were conducted to examine the influence of varying planting dates or egg application dates on plant damage (Branson \& Sutter 1986; Hibbard et al. 1999; Hibbard et al. 2008), however with contradicting results. While Branson and Sutter (1986) found higher damage ratings when the plants were infested with WCR after their emergence than on their planting date, Hibbard et al. (1999) detected heavier root damages when the plants were infested at the date of sowing instead of an infestation at the 2- or 5-leaf stage of maize. Hibbard et al. (1999) assumed this effect due to uncommon high experimental temperatures in their field. Bergman \& Turpin (1984) and Musick et al. (1980) found that larval survival and larval development of WCR depend on the availability of maize roots at the hatching 
date of early hatched larvae. This resulted in changes of population dynamics and seasonal occurrence of life stages in the field occurred by a delay of the sowing date. In contrast, Fisher et al. (1990) did not find any influence of the sowing date on WCR immature stages or adult occurrence.

In this experiment the influence of a moderate delay of the maize sowing date under simulated a) today's temperature regime and b) a changed temperature regime with elevated spring and summer temperatures by $2^{\circ} \mathrm{C}$ in Northern Germany was examined. We hypothesized that a late sowing date leads to a (i) retarded larval development and (ii) a diminished larval recovery of WCR and that these effects are enhanced under the change temperature regime. 


\section{Material and Methods}

The experiment proceeded in section a) with a simulated temperature regime of today (1971-2000) and section b) with a global warming scenario with a by $2^{\circ} \mathrm{C}$ elevated temperature regime (change regime). Each section of the experiment started with egg application when the mean temperature of $11^{\circ} \mathrm{C}$ as a threshold for the development of WCR eggs (Wilde 1971) was reached. Therefore temperature simulation started a) at Julian Day (JD) 121 under the temperature regime of today and b) at JD 107 under the by $2^{\circ} \mathrm{C}$ changed temperature regime. Meteorological data were compiled by the DWD (Deutscher Wetterdienst), comprising the period from 1971 to 2000 at the location of Lingen. These data were used to calculate weekly adjusted mean temperatures in Northern Germany (Table 1). Lingen was chosen because of its location in a high risk area for establishment of high populations of WCR and thus a heavy damage potential (Schaafsma et al. 1991) because of the high frequencies of continuous maize. The experiment ended at a temperature sum of 370 day-degrees $\left(D^{\circ}\right)$ with a base temperature of $11^{\circ} \mathrm{C}$ after egg application. $13 \mathrm{~cm}$ diameter pots were filled with Haplic Luvisol (sand/ silt/ clay-content: 3.0\% / 55.2\% / 41.8\%; $\mathrm{pH}\left(\mathrm{H}_{2} \mathrm{O}\right)$ 7.6; C/N-ratio 15.8) from a field near Goettingen. The soil had been homogenized with a soil shredder (Unifix 300, Moeschle, Ortenberg, Germany). Eggs from the non-diapausing WCR laboratory population (USDA-ARS, North Central Agricultural Research Laboratory, Brookings, North Dakota, USA (Branson 1976)) were used in the experiment. The eggs were stored below $8^{\circ} \mathrm{C}$ until their use. They were washed with a sieve $(250 \mu \mathrm{m})$ from the soil and added to a sterile $0.15 \%$ agar solution. Near the brink of each pot 50 viable eggs were applied using a pipette (Multipipette Plus, Eppendorf, Hamburg, Germany) into the soil at a depth of $7 \mathrm{~cm}$. For each temperature regime 64 plants were sown (with 32 plants per sowing date). All maize seeds were pregerminated for $24 \mathrm{~h}$ on sterile filter paper at $25^{\circ} \mathrm{C}$ and sown into $3 \mathrm{~cm}$ depth into the middle of the pots at two different sowing dates, half at JD 121 the other half at JD 135. To monitor hatching rate and hatching date, 18 hatch tests for the temperature regime of today regime and 16 for the $2^{\circ} \mathrm{C}$ enhanced temperature regime were prepared. $1 \mathrm{ml}$ of the egg solution was added into Petri dishes with sterile moistened filter paper and the hatch tests were buried in pots with soil and reared under experimental conditions. The eggs were counted and daily checked for hatching when a temperature sum of $100 \mathrm{D}^{\circ}$ was reached. Relative humidity was adjusted to $60 \% \pm 5 \%$ and the photoperiod was $14 \mathrm{~h}: 10 \mathrm{~h}$ 
(light:darkness). The experiment was performed in climate cabinets (Mytron WB 750 KFL, Mytron Bio- und Solartechnik GmbH, Heiligenstadt, Germany) with by data logger (Voltcraft DL-120 TH, Conrad Electronic SE, Hirschau, Germany) controlled and adjusted weekly mean temperatures. At the end of the experiment plant height was measured and larvae were extracted from the soil using a high gradient Kempson device (Kempson et al. 1963) for 2 days at $60^{\circ} \mathrm{C}$. Larvae were counted and head capsule width was measured using a binocular microscope with integrated object micrometer to determine larval instar (Hammack et al. 2003). Thereafter larvae were dried at $60^{\circ} \mathrm{C}$ for three days and dry weight was measured using a micro scale (MC5, Sartorius, Goettingen, Germany) with measuring accuracy of $0.001 \mathrm{mg}$. 


\section{Data analysis}

All statistical tests were performed using Statistica 10 (StatSoft ${ }^{\circledR}$, Tulsa, USA). All data were tested for the normal distribution with the Shapiro-Wilk-test and by visual observation of histograms. Levene's test was carried out to test the equality of variances. Required day-degrees $\left(D^{\circ}\right)$ (dependent variable) for hatching of the different temperature regimes (grouping variable) were tested for differences with Mann-Whitney U-test (MWU-test). The influence of the temperature regime (grouping variable) on hatching rate (dependent variable), respectively on Julian Day (JD) of hatch (dependent variable) was also calculated with the MWU-test.

To examine how the sowing date (grouping variable) influenced the WCR-larval development expressed as log transformed dry weight and headcapsule width (dependent variable) a Student's t-test for each temperature regime was performed. The effect of sowing date (grouping variable) on larval recovery (dependent variable) was tested with the MWU-test for both temperature regimes.

The effect of sowing date (grouping variable) on plant height at the extraction date (dependent variable) was tested with the MWU-test.

A simple regression was used to quantify the effect of plant height (predictor variable) on WCR development measured as log transformed dry weight $(\mu \mathrm{g})$ and as headcapsule width $(\mu \mathrm{m})$ (dependent variables). Effect of plant height $(\mathrm{cm})$ as the predictor variable on recovery rate (\%) as dependent variable was quantified with a simple regression. 


\section{Results}

\section{$\underline{\text { Temperature regime and western corn rootworm hatch }}$}

Temperature regimes did neither affect the required temperature sum $\left(D^{\circ}\right)$ for hatch (MWU-test: $P=0.77, U=135.00 ; Z=-0.29$ ), nor the hatching rate (MWU-test: $P=0.13$, $U=99.00 ; Z=1.54) .50 \%$ hatch occurred at a temperature sum of $290.2 \mathrm{D}^{\circ}$ under the today temperature regime, respectively at a temperature sum of $290.1 \mathrm{D}^{\circ}$ under the change regime. The Julian Day of 50\% hatch accelerated from JD 195 under the temperature regime of today to JD 177 under the change regime (Table 2).

\section{Sowing date and larval development}

Under the temperature of today the sowing dates used in the experiment did not influence larval development measured as log transformed larval dry weight (Student's t-test: $P=0.63, t(56)=-0.48$, Figure $1 \mathrm{~A}$ ) or headcapsule width (Student's ttest: $P=0.80, t(56)=0.26)$.

Under the climate change temperature regime the late sowing date on JD 135 had a negative effect on larval development. The larvae of the early sown plants on JD 121 had a higher dry weight (Student's t-test: $P=0.043, t(62)=2.06$, Figure $1 \mathrm{~B}$ ) and wider headcapsules (Student's t-test: $P=0.006, t(62)=2.88$ ).

\section{Sowing date and larval recovery rate}

There were no differences between the recovery rates (\%) of the two sowing dates under today's temperature regime (MWU-test: $P=0.16, U=407.00 ; Z=-1.40$ ) and under the change regime (MWU-test: $P=0.29, U=432.00 ; Z=1.07$ ).

\section{Sowing date and plant height}

Under today's temperature regime sowing date did not affect plant height on the extraction date (MWU-test: $P=0.152, U=327.50 ; Z=-1.43$; Figure $2 \mathrm{~A}$ ). On the change regime early sown plants were significantly higher than late sown plants (MWU-test: $P=0.017, U=334.50 ; Z=2.38$; Figure $2 \mathrm{~B}$ ). 
$\underline{\text { Influence of plant height on larval development and recovery rate }}$ Larval development measured as log larval dry weight and as headcapsule width was highly positively correlated with plant height on both temperature regimes. Regression equations are shown in Table 3.

Plant height was also positive correlated with recovery rate under the temperature regime of today $\left(P<0.01\right.$; regression equation: $\left.y=48.2748+0.3751^{*} x ; R^{2}=0.19\right)$ and the change regime $\left(P<0.01\right.$; regression equation: $\left.y=40.7442+0.4053^{*} x ; R^{2}=0.26\right)$. 


\section{Discussion}

The different temperature regimes in our experiment did not affect larval hatch and development directly. Indeed, larval hatch occurred at JD 195 under today's regime compared to JD 177 at the change regime because of the earlier start of egg development, but there were no differences between the hatching rates detectable. The temperature sum necessary for $50 \%$ hatch was equal with $290.2 \mathrm{D}^{\circ}$ (today) and $295.1 D^{\circ}$ (change) between the two temperature regimes: this was expected because the temperature sum is a very reliable predictor for certain developmental events under constant temperature regimes (Damos \& Savopoulou-Soultani 2012). The temperature sum was also consistent to the $292 \pm 69 D^{\circ}$ Fisher (1989) observed in his laboratory experiment with constant temperatures and simulated field temperatures for $50 \%$ hatch.

At the temperature regime of today the sowing dates on JD 121 and 135 did not influence WCR larval development, but under the change regime larval development was retarded at the late sown plants. This influence of the sowing date at the change temperature regime was certainly an effect of the synchrony of larval hatch and plant phenology. At the extraction date there were no significant differences between plant height of early and late sown plants under today's temperature regime, because of the low simulated temperatures when the experiment started und the resulting small difference in the temperature sum between the two sowing dates (15.4 $\mathrm{D}^{\circ}$ with a base of $\left.11^{\circ} \mathrm{C}\right)$. Under the change regime early sown plants were slightly higher at the extraction date, compared with the plants planted at JD 135 (44.4 D difference in temperature sum). The eggs received $50.4 \mathrm{D}^{\circ}$ at the change regime before the JD 135 plants were sown. The root biomass was not quantified in our experiment, but we assume that higher plants at the extraction date had a higher root biomass. Therefore a better food supply for the neonate larvae was provided as the plant heights at hatch and at the extraction date were highly correlated (data not shown). This assumption accords with the hypotheses by Branson et al. 1982 and Branson et al. 1983 that the availability of root biomass at the hatching date rather than the total root biomass, determines the survival of neonate larvae (Branson et al. 1982; Branson et al. 1983). Early hatched larvae on poor developed plants presumably died due to starvation because of the lack of sufficient root material (Bergman \& Turpin 1984; Branson 1989; Hibbard et al. 1999; Musick et al. 1980) and the lack of preferred bigger newly grown nodal roots for older larvae (Hibbard et al. 2008). 
Additionally well grown plants have a high root regrowth potential caused by a high photosynthetic biomass (Godfrey et al. 1993) which would lead to a high amount of suitable young roots for larval feeding. Food quality and quantity both are essential factors for herbivores (Awmack \& Leather 2002). Not only the amount of ingested food, but also the quality such as nitrogen and root phytosterol content (Moeser \& Vidal 2004) regulates WCR larval growth. Chiang (1973) reported that larvae preferred different root parts depending on their body size and age. Although we found that the larvae developed well an bigger plants, it can be expected that larval development on older plants would be retarded, due to the loss of nutritional value at aged plants (Chege et al. 2005) and the termination of root growth in plants at the generative growth stages (Robert et al. 2012).

We could not detect the negative effect of a late sowing on larval recovery other authors described for their field experiments (Bergman \& Turpin 1984; Musick et al. 1980). However, these authors delayed the sowing up to early June for more than 6 weeks, not only two weeks, therefore our differences in plant growth were much lower. Well grown plants affected the recovery rate significantly positive. It is most likely that we would get similar results when we used these late planting dates, but such a late sowing would lead to considerable yield losses. On the other hand, the plant infestation rates by WCR larvae diminish at later sown plants (Chiang 1973). Another explanation that we found no significant differences in recovery between the treatments could be the low competition between the larvae because of the low infestation rates of only 50 eggs per plant (Branson et al. 1980). Whether plant damage tends to be positively or negatively affected by an early sowing has been and still is a topic in WCR research that results in conflictive discussions (Branson \& Sutter 1986; Hibbard et al. 1999; Levine \& Oloumi-Sadeghi 1991). Further investigation could be useful to find a balance between the disruption of plantherbivore synchrony and yield losses under a changing climate with its predicted longer growing seasons (Cannon 1998). Overall with a later sowing of maize under a changing climate it can be presumed that more heat units for larval development accumulate before maize sowing, thus increasing larval mortality due to starvation. 


\section{References}

Aragón, P. \& Lobo, J.M., 2012. Predicted effect of climate change on the invasibility and distribution of the Western corn rootworm. Agricultural and Forest Entomology, 14(1), pp.13-18.

Awmack, C.S. \& Leather, S.R., 2002. Host plant quality and fecundity in herbivorous insects. Annual Review of Entomology, 47(1), pp.817-844.

Baufeld, P., Enzian, S. \& Motte, G., 1996. Establishment potential of Diabrotica virgifera in Germany. EPPO Bulletin, 26(3-4), pp.511-518.

Bergman, M.K. \& Turpin, F.T., 1984. Impact of corn planting date on the population dynamics of corn rootworms (Coleoptera: Chrysomelidae). Environmental Entomology, 13(3), pp.898-901.

Branson, T.F. et al., 1983. Resistance to larvae of Diabrotica virgifera virgifera in three experimental maize hybrids. Environmental Entomology, 12(5), pp.1509-1512.

Branson, T.F., 1989. Survival of starved neonate larvae of Diabrotica virgifera virgifera LeConte (Coleoptera: Chrysomelidae). Journal of the Kansas Entomological Society, pp.521-523.

Branson, T.F., 1976. The selection of a non-diapause strain of Diabrotica virgifera (Coleoptera: Chrysomelidae). Entomologia Experimentalis et Applicata, 19(2), pp.148-154.

Branson, T.F., Suiter, G.R. \& Fisher, J.R., 1982. Comparison of a tolerant and a susceptible maize inbred under artificial infestations of Diabrotica virgifera virgifera: Yield and Adult Emergence. Environmental Entomology, 11(2), pp.371-372.

Branson, T.F. \& Sutter, G.R., 1986. Influence of application date on damage Rresulting from controlled infestations with eggs of Diabrotica virgifera virgifera (Coleoptera: Chrysomelidae). Journal of Economic Entomology, 79(3), pp.838-839.

Branson, T.F., Sutter, G.R. \& Fisher, J.R., 1980. Plant response to stress induced by artificial infestations of western corn rootworm. Environmental Entomology, 9(2), pp.253-257.

Buse, A. \& Good, J., 1996. Synchronization of larval emergence in winter moth (Operophtera brumata L.) and budburst in pedunculate oak (Quercus robur L.) under simulated climate change. Ecological Entomology, 21(4), pp.335-343.

Cannon, R.J.C., 1998. The implications of predicted climate change for insect pests in the UK, with emphasis on non-indigenous species. Global Change Biology, 4(7), pp.785-796. 
Chege, P.G., Clark, T.L. \& Hibbard, Bruce E., 2005. Alternate host phenology affects survivorship, growth, and development of western corn rootworm (Coleoptera: Chrysomelidae) larvae. Environmental Entomology, 34(6), pp.1441-1447.

Chiang, H.C., 1973. Bionomics of the northern and western corn rootworms. Annual Review of Entomology, 18(1), pp.47-72.

Ciosi, M. et al., 2008. Invasion of Europe by the western corn rootworm, Diabrotica virgifera virgifera: multiple transatlantic introductions with various reductions of genetic diversity. Molecular Ecology, 17(16), pp.3614-3627.

Collier, R.H. et al., 1991. Possible impact of global warming on cabbage root fly (Delia radicum) activity in the UK. Annals of Applied Biology, 118(2), pp.261271.

Damos, P. \& Savopoulou-Soultani, M., 2012. Temperature-driven models for insect development and vital thermal requirements. Psyche: A Journal of Entomology, 2012, pp.1-13.

Deutsch, C.A. et al., 2008. Impacts of climate warming on terrestrial ectotherms across latitude. Proceedings of the National Academy of Sciences of the United States of America, 105(18), pp.6668-6672.

Dewar, R.C. \& Watt, A.D., 1992. Predicted changes in the synchrony of larval emergence and budburst under climatic warming. Oecologia, 89(4), pp.557559.

EPPO, 2011. Diabrotica virgifera. Available at:

http://www.eppo.org/QUARANTINE/Diabrotica_virgifera/diabrotica_virgifera.ht $\mathrm{m}$ [Accessed January 5, 2012].

Fisher, J.R., 1989. Hatch of Diabrotica virgifera virgifera (Coleoptera: Chrysomelidae) eggs exposed to two different overwintering and hatch regimes. Journal of the Kansas Entomological Society, 62(4), pp.607-610.

Fisher, J.R., Sutter, G.R. \& Branson, T.F., 1990. Influence of corn planting date on the life stage development and phenology of Diabrotica virgifera virgifera. Entomologia Experimentalis et Applicata, 54(3), pp.219-224.

Godfrey, L., Meinke, L.J. \& Wright, R.J., 1993. Affects of larval injury by western corn rootworm (Coleoptera: Chrysomelidae) on gas exchange parameters of field corn. Faculty Publications: Department of Entomology. Available at: http://digitalcommons.unl.edu/entomologyfacpub/88.

Gray, M.E. et al., 2009. Adaptation and invasiveness of western corn rootworm: intensifying research on a worsening pest. Annual Review of Entomology, 54, pp.303-321.

Gregory, P.J. et al., 2009. Integrating pests and pathogens into the climate change/food security debate. Journal of Experimental Botany, 60(10), pp.2827-2838. 
Hammack, L. et al., 2003. Larval sampling and instar determination in field populations of northern and western corn rootworm (Coleoptera: Chrysomelidae). Journal of Economic Entomology, 96, pp.1153-1159.

Hibbard, B. E. et al., 1999. Controlled field infestations with western corn rootworm (Coleoptera: Chrysomelidae) eggs in Missouri: effects of egg strains, infestation dates, and infestation levels on corn root damage. Journal of the Kansas Entomological Society, 72(2), pp.214-221.

Hibbard, B. E. et al., 2008. Maize phenology affects establishment, damage, and development of the western corn rootworm (Coleoptera: Chrysomelidae). Environmental Entomology, 37(6), pp.1558-1564.

Kahler, A. et al., 1985. Root damage by western corn rootworm and nutrient content in maize. Agron. J, 77, pp.769-774.

Kempson, D., Lloyd, M. \& Ghelardi, R., 1963. A new extractor for woodland litter. Pedobiologia, 3, pp.1-21.

Levine, E. \& Oloumi-Sadeghi, H., 1991. Management of Diabroticite rootworms in corn. Annual Review of Entomology, 36(1), pp.229-255.

Melhus, I.E., Painter, R.H. \& Smith, F.O., 1954. A search for resistance to the injury caused by species of Diabrotica in the corns of Guatemala. lowa State Coll. J. Sci., 29, pp.75-94.

Moeser, J. \& Vidal, S., 2004. Response of larvae of invasive maize pest Diabrotica virgifera virgifera (Coleoptera: Chrysomelidae) to carbon/nitrogen ratio and Phytosterol content of european maize varieties. Journal of Economic Entomology, 97(4), pp.1335-1341.

Musick, G.J. et al., 1980. Impact of planting dates of field corn on beetle emergence and damage by the western and the northern corn rootworms in the Corn Belt. Annals of the Entomological Society of America, 73, pp.207-215.

Musolin, D.L., Tougou, D. \& Fujisaki, K., 2010. Too hot to handle? Phenological and life-history responses to simulated climate change of the southern green stink bug Nezara viridula (Heteroptera: Pentatomidae). Global Change Biology, 16(1), pp.73-87.

Parmesan, C., 2007. Influences of species, latitudes and methodologies on estimates of phenological response to global warming. Global Change Biology, 13(9), pp.1860-1872.

Porter, J.H., Parry, M.L. \& Carter, T.R., 1991. The potential effects of climatic change on agricultural insect pests. Agricultural and Forest Meteorology, 57(1-3), pp.221-240.

Rannow, S. et al., 2010. Potential impacts of climate change in Germany-ldentifying regional priorities for adaptation activities in spatial planning. Landscape and Urban Planning, 98(3-4), pp.160-171. 
Riedell, W.E., 1990. Rootworm and mechanical damage effects on root morphology and water relations in maize. Crop Science, 30(3), p.628.

Robert, C.A.M. et al., 2012. A specialist root herbivore exploits defensive metabolites to locate nutritious tissues. Ecology Letters, 15(1), pp.55-64.

Schaafsma, A.W., Whitfield, G.H. \& Ellis, C.R., 1991. A temperature-dependent model of egg development of the Western Corn Rootworm, Diabrotica virgifera virgifera LeConte (Coleoptera: Chrysomelidae). The Canadian Entomologist, 123, pp.1183-1197.

Shaw, J.T., Paullus, J.H. \& Luckmann, W.H., 1978. Corn rootworm oviposition in Soybeans. Journal of Economic Entomology, 71(2), pp.189-191.

Stainforth, D.A. et al., 2005. Uncertainty in predictions of the climate response to rising levels of greenhouse gases. Nature, 433(7024), pp.403-406.

Stange, E.E. \& Ayres, M.P., 2010. Climate Change Impacts: Insects. In John Wiley \& Sons, Ltd, ed. Encyclopedia of Life Sciences. Chichester, UK: John Wiley \& Sons, Ltd. Available at: http://www.els.net/WileyCDA/ElsArticle/reflda0022555.html [Accessed February 9, 2012].

Szalai, M. et al., 2010. Generational growth rate estimates of Diabrotica virgifera virgifera populations (Coleoptera: Chrysomelidae). Journal of Pest Science, 84, pp.133-142.

Walther, G.-R. et al., 2002. Ecological responses to recent climate change. Nature, 416(6879), pp.389-395.

Wesseler, J. \& Fall, E.H., 2010. Potential damage costs of Diabrotica virgifera virgifera infestation in Europe - the "no control" Scenario. , 134, pp.385-394.

Whittaker, J.B. \& Tribe, N.P., 1996. An altitudinal transect as an indicator of responses of a spittlebug (Auchenorrhyncha: Cercopidae) to climate change. European Journal of Entomology, 93(3), pp.319-324.

Wilde, G.E., 1971. Temperature effect on development of Western Corn Rootworm eggs. Journal of the Kansas Entomological Society, 44(2), pp.185-187.

Ziska, L.H. et al., 2010. Invasive species and climate change: an agronomic perspective. Climatic Change, 105(1-2), pp.13-42. 


\section{Annex}

\section{$\underline{\text { Tables }}$}

Table 1: weekly adjusted experimental mean temperature of today $\mathbf{T}_{\text {today }}\left(\mathrm{C}^{\circ}\right)$ calculated from historical (1971-2000) data from the DWD (Deutscher Wetterdienst) in Lingen and the by $2^{\circ} \mathrm{C}$ elevated temperature regime $\mathbf{T}$ change

\begin{tabular}{ccc} 
Julian Day & $\mathrm{T}_{\text {today }}\left({ }^{\circ} \mathrm{C}\right)$ & $\mathrm{T}_{\text {change }}\left({ }^{\circ} \mathrm{C}\right)$ \\
\hline $107-113$ & & 11 \\
$114-120$ & & 12 \\
$121-127$ & 11.4 & 13.4 \\
$128-134$ & 12.8 & 14.8 \\
$135-141$ & 13.9 & 15.9 \\
$142-148$ & 13.9 & 15.9 \\
$149-155$ & 14.9 & 16.9 \\
$156-162$ & 15.4 & 17.4 \\
$163-169$ & 15.5 & 17.5 \\
$170-176$ & 15.5 & 17.5 \\
$177-183$ & 16.5 & 18.5 \\
$184-190$ & 17.9 & 19.9 \\
$191-197$ & 17.7 & \\
$198-204$ & 17.2 & \\
$205-211$ & 17.9 & \\
\hline
\end{tabular}

Table 2: Julian day (JD) of $50 \%$ larval hatching under the temperature regime of Lingen calculated from 1971-2000 (today) and the by $2^{\circ} \mathrm{C}$ elevated temperature regime (change) (replicates = hatch tests: $\mathrm{N}_{\text {totay }}=18 ; \mathrm{N}_{\text {change }}=16$ ).

\begin{tabular}{lccccc} 
temperature regime & JD 50\% hatch & $\mathrm{N}$ & JD min & JD max & SD \\
\hline today & 194.97 & 18 & 183.5 & 206.3 & 6.9 \\
change & 176.75 & 16 & 170.0 & 182.1 & 3.3 \\
\hline
\end{tabular}


Table 3: Regression equations of plant height $(\mathrm{cm})$ as predictor and log larval dry weight $(\mu \mathrm{g})$ respectively headcapsule width $(\mu \mathrm{m})$ as dependent variable at the temperature regime of today and the change regime

\begin{tabular}{llcrrr}
$\begin{array}{l}\text { temperature } \\
\text { regime }\end{array}$ & dependent Variable & $y$ & $F$ & $P$ & $R^{2}$ \\
\hline $\begin{array}{l}\text { today } \\
\text { change }\end{array}$ & log larval dry weight & $\mathrm{y}=1.09+0.01^{*} \mathrm{x}$ & 11.31 & $<0.01$ & 0.17 \\
& $\log$ larval dry weight & $\mathrm{y}=1.16+0.01^{*} \mathrm{x}$ & 72.68 & $<0.01$ & 0.54 \\
& & & & & \\
today & headcapsule width & $\mathrm{y}=175.96+1.85^{*} \mathrm{x}$ & 16.70 & $<0.01$ & 0.23 \\
change & headcapsule width & $\mathrm{y}=177.52+2.53^{*} \mathrm{x}$ & 109.15 & $<0.01$ & 0.64 \\
\hline
\end{tabular}


$\underline{\text { Figures }}$

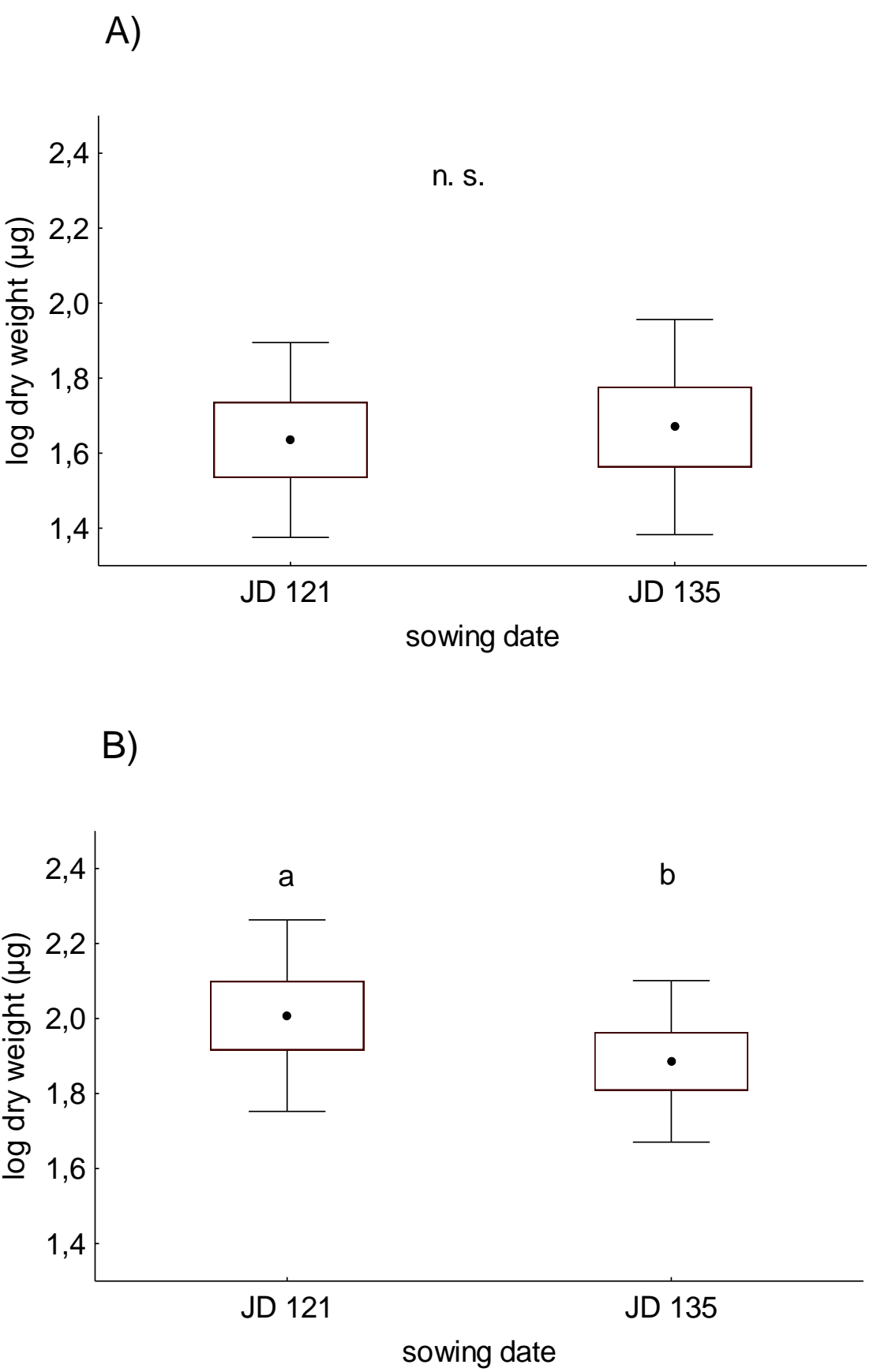

Figure 1: Influence of sowing date in Julian days (JD) on larval development measured as log larval dry weight $(\mu \mathrm{g})$ at the temperature regime of today $(A)$ and the change regime $(B)$ (Student's t-test; dot $=$ mean, box $=$ mean $\pm 0.95 \mathrm{Cl}$, whisker = mean $\pm \mathrm{SD}$; letters indicate significant statistical differences; $n$. s. = not significant: $P>0.05$; replicates $=$ plants: $N_{J D} 121$ $=32 ; N_{J D} 135=32$ for each temperature regime). 
A)

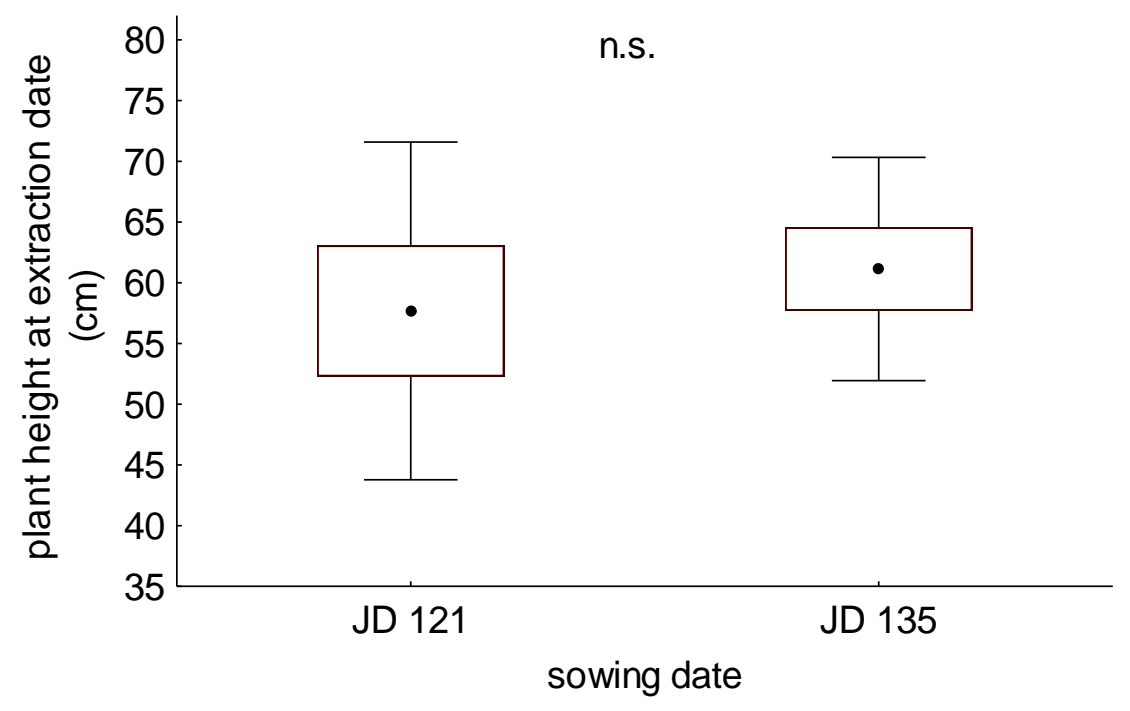

B)

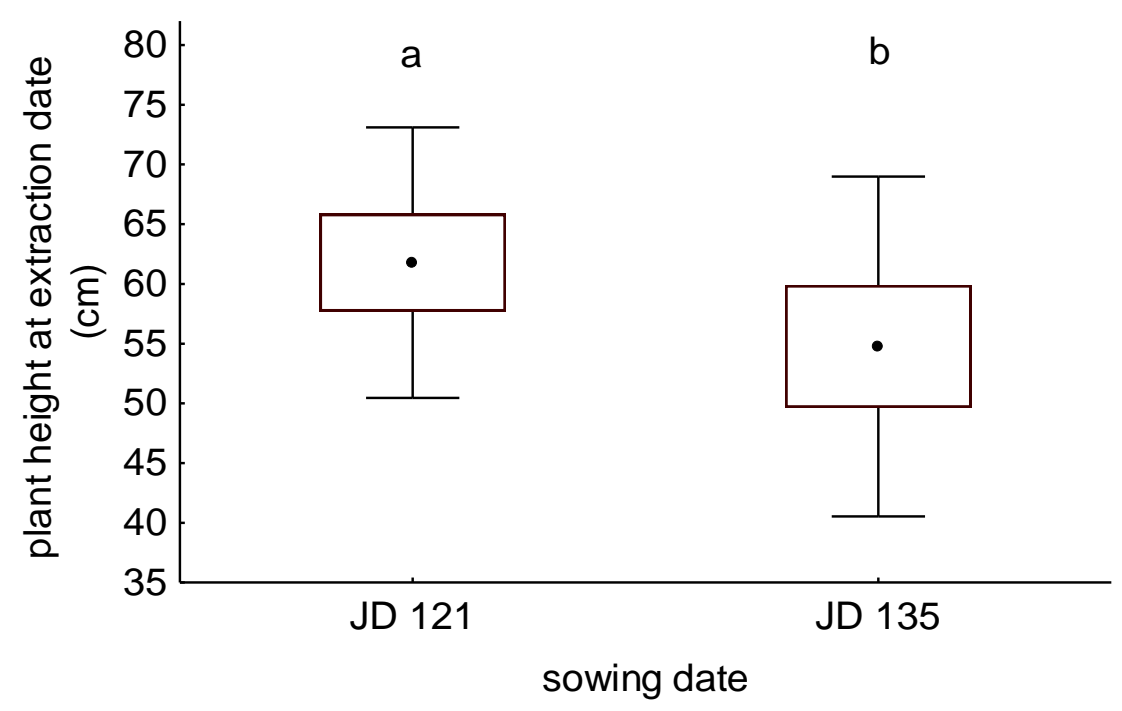

Figure 2: Influence of sowing date in Julian days (JD) on plant height $(\mathrm{cm})$ at the temperature regime of today $(A)$ and the change regime $(B)$ (MWU-test; dot $=$ mean, box $=$ mean $\pm 0.95 \mathrm{Cl}$, whisker = mean $\pm S D$; letters indicate significant statistical differences; $n$. s. = not significant: $P$ $>0.05$; replicates = plants: $N_{\text {JD } 121}=32 ; N_{J D} 135=32$ for each temperature regime). 
Western corn rootworm (Diabrotica virgifera virgifera LeConte) development under constant and varying temperature regimes

\begin{abstract}
Forecasts of western corn rootworm (WCR) hatch and development in the field depend on models using experimentally determined day-degrees $\left(D^{\circ}\right)$. For constant temperature regimes this temperature sum is a reliable parameter to predict hatch and development of WCR larvae. In experiments in climate cabinets we evaluated the effects of varying day-night $\left(4^{\circ} \mathrm{C}\right.$ and $6^{\circ} \mathrm{C}$ difference) temperature regimes compared to equivalent the constant temperature regime on hatch, development and recovery of WCR larvae.

Varying day-night temperatures resulted in earlier larval hatch and accelerated larval development due to direct temperature effects like the rate summation (Kaufmann effect) and enhanced plant growth, with fastest development by the $6^{\circ} \mathrm{C}$-difference regime. For western corn rootworm the temperature sum needed for hatch in the field are overestimated when they are determined by models based on constant experimental temperatures.

Hatching rates and recovery were not affected by temperature, but recovery was positively affected by plant height.

For herbivorous insects, such as WCR, plant growth effects induced by varying temperature regimes may result in increased variation in temperature based developmental parameters. These need to be taken into account to improve models on WCR hatch, development and optimal timing of control strategies especially for Northern German temperature conditions.
\end{abstract}




\section{Introduction}

Development of poikilotherms like insects and plants is highly temperature dependent (Beck 1983; Behrens et al. 1983; Liu, Zhang, \& Zhu 1995; Bergant \& Trdan 2006). There are species specific requirements for the amount of thermal energy (thermal constant) needed to accomplish different life stages (Damos \& Savopoulou-Soultani 2012). This thermal energy is measured as sum of effective temperature, which is calculated as temperature range between lower threshold of development (no development below this temperature) and upper threshold of development (no development above this temperature) over a specific time (typically day: day-degrees $\left(D^{\circ}\right)$; Damos \& Savopoulou-Soultani 2012).

Day-degrees and the thermal thresholds for development are reliable predictors for key data of poikilotherms like dormancy, insect egg hatch, budburst or plant flowering at constant temperatures. However, in most terrestric habitats varying day/night temperatures are pronounced and constant temperature regimes, typically set-up in laboratory tests, are thus unlikely to mimic the influences the insects are exposed to under field conditions. A review by (Howe 1967) has already pointed out these important shortcomings using constant temperature regimes. While for some species no detectable differences with regard to development at constant versus variable temperature regimes have been reported (Hagstrum \& Leach 1973; Humpesch 1982) other species showed either retarded or accelerated development under varying temperatures (Hagstrum \& Hagstrum 1970). These differences were dependent on species, life stage and temperature range (Kaufmann 1932; Hagstrum \& Leach 1973). Understanding the impact of varying temperature regimes on biological key data is essential in improving predictions on the developmental time of pest species and will help to build upon forecasting models and ensure effective pest management strategies (Spencer et al. 2009).

Subject of our study were the immature stages of western corn rootworm (Diabrotica virgifera virgifera LeConte; WCR).

The WCR is an invasive quarantine maize pest in Europe which was accidentally introduced in the late seventies or early eighties of the 20th century from North America to Serbia (Szalai et al. 2010). It was detected in 1992 near Belgrade airport (Gray et al. 2009). In 2010 this pest has already been reported from more than 20 European countries (EPPO 2011). During the last 20 years at least 5 introductions into Europe took place (Ciosi et al. 2008). In case of an establishment of this pest in 
most maize growing regions in Europe damage costs are expected to sum up to more than 470 million Euro per year (Wesseler \& Fall 2010).

Western corn rootworm females lay eggs in autumn in the maize field, rarely in other crops. The eggs overwinter in the soil in diapause which ends in spring at a threshold temperature of $11^{\circ} \mathrm{C}$ (Wilde 1971). Larvae hatch and infest the host plant roots. Most damage is caused by the root feeding of larvae, which upsets nutrient and water uptake and lowers plant stability (Kahler et al. 1985; Riedell 1990).

We study the effect of diurnal varying temperatures compared with constant temperatures on western corn rootworm immature stages under quarantine conditions.

Whereas several papers report on WCR larval development under constant temperatures (Kuhlman, Howe, \& Luckmann 1970; Wilde 1971; Jackson \& Elliott 1988; Schaafsma, Whitfield, \& Ellis 1991), we are aware of only two paper yet on WCR egg development under varying temperatures (Levine, Oloumi-Sadeghi, \& Ellis 1992) respectively under a simulated natural temperature regime (Fisher 1989). So far no data on the development of WCR larvae under Central European conditions or more specifically, under Northern German conditions have been published. For improving pest management strategies, such as optimal application time of insecticides knowledge on the hatching time of overwintering eggs and development pattern of the larvae are necessary.

In this study we investigated WCR hatching rate and hatching date, larval development, and recovery under constant and varying ambient Northern Germany temperature regimes under consideration of plant growth effects.

We hypothesize that varying ambient temperatures compared to a constant temperature will result in (i) an earlier WCR larval hatch, (ii) a higher hatching rate, (iii) an accelerated development rate and (iv) a higher larval recovery.

We conducted a second experiment to compare the effects of high, mediate and low constant development temperatures and their diurnal $(12 \mathrm{~h} / 12 \mathrm{~h})$ by $8^{\circ} \mathrm{C}$ varying counterparts of the same mean on the needed thermal energy for WCR hatch. We expected that less thermal energy necessary under the varying temperatures. 


\section{Material and Methods}

\section{Experiment 1}

Maize seeds (cultivar Susann, Saaten Union, Germany) were pregerminated for $24 \mathrm{~h}$ on moistened filter paper at $25^{\circ} \mathrm{C}$ and were sown individually into pots $(10 \mathrm{~cm}$ diameter) with Haplic Luvisol (sand/ silt/ clay-content: 3.0\% / 55.2\% / 41.8\%; pH $\left(\mathrm{H}_{2} \mathrm{O}\right)$ 7.6; C/N-ratio 15.8) from a field near Goettingen. The soil was homogenized with a soil shredder (Unifix 300, Moeschle, Ortenberg, Germany). The plants were kept in the greenhouse $\left(22^{\circ} \mathrm{C} \pm 4^{\circ} \mathrm{C}\right) .245$ one week old maize plants of equal size were selected for the experiment (BBCH 12 (Lancashire et al. 1991)). Non-diapausing WCR eggs (USDA-ARS, North Central Agricultural Research Laboratory, Brookings, North Dakota, USA (Branson 1976)) were stored below $8^{\circ} \mathrm{C}$ until their use. Eggs were washed with a sieve $(250 \mu \mathrm{m})$ from the soil and added to a sterile $0.15 \%$ agar solution. Each plant was infested with 20 viable eggs using a pipette (Multipipette Plus, Eppendorf, Hamburg, Germany) into the soil at a depth of $5 \mathrm{~cm}$. To monitor hatching rate and hatching date, hatch tests were prepared. $2 \mathrm{ml}$ of egg solution was added into each of 24 Petri dishes with sterile moistened filter paper and 4 randomly chosen Petri dishes per cabinet were reared under experimental conditions and 4 Petri dishes were placed into an incubator with constant $25^{\circ} \mathrm{C}$ with $60 \% \mathrm{RH}$ to observe hatching patterns (one Petri dish as one replicate) under experimental and optimal development conditions. The eggs were counted and daily checked for hatching.

49 infested plants per cabinet were randomly placed into 5 climate cabinets (Mytron WB 750 KFL, Mytron Bio- und Solartechnik GmbH, Heiligenstadt, Germany) with by data logger (Voltcraft DL-120 TH, Conrad Electronic SE, Hirschau, Germany) controlled equivalent adjusted weekly mean temperatures. Meteorological data compiled by the DWD (Deutscher Wetterdienst), comprising the period of 1971 to 2000 at the location of Lingen were used to calculate weekly adjusted mean temperatures in Northern Germany (Table 1). Lingen was chosen because of its location in a high risk area for an establishment of a high population of WCR and thus heavy damage potential (Schaafsma, Baufeld, \& Ellis 1999) because of the high frequencies of continuous maize. In one cabinet the constant (with no daily variations) temperature regime of Lingen was established, two cabinets had a daynight $(12 \mathrm{~h} / 12 \mathrm{~h})$ difference of $4^{\circ} \mathrm{C}$ and two cabinets a day-night $(12 \mathrm{~h} / 12 \mathrm{~h})$ difference 
of $6^{\circ} \mathrm{C}$. The experiment started with the temperature-simulation at Julian Day (JD) 121 as sowing date and the first mean temperature above the base temperature of $11^{\circ} \mathrm{C}$ as threshold of development (Wilde 1971). Relative humidity was adjusted to $60 \% \pm 5 \%$ and the photoperiod was $12 \mathrm{~h}$ : $12 \mathrm{~h}$ (light: darkness).

One week after the first hatch in the hatch tests and henceforward 7 plants per cabinet (one plant as one replicate) were randomly assessed per week. Plant height was measured and larvae were extracted from the soil using a high gradient Kempson device (Kempson, Lloyd, \& Ghelardi 1963) for 2 days at $60^{\circ} \mathrm{C}$. The larvae were counted and the head capsule width was measured using a binocular microscope with an integrated object micrometer to determine larval instar (Hammack et al. 2003). Thereafter larvae were dried at $60^{\circ} \mathrm{C}$ for three days and dry weight was measured using a micro scale (MC5, Sartorius, Goettingen, Germany) with measuring accuracy of $0.001 \mathrm{mg}$.

\section{Experiment 2}

In the second experiment eggs were washed with a sieve $(250 \mu \mathrm{m})$ from soil and added to a sterile $0.15 \%$ agar solution. $1 \mathrm{ml}$ of egg solution was added into each of 96 Petri dishes with sterile moistened filter paper. 16 Petri dishes per cabinet were randomly chosen and the eggs were counted. The eggs were reared under 6 different experimental temperatures: high $\left(20^{\circ} \mathrm{C}\right)$, mediate $\left(17^{\circ} \mathrm{C}\right)$ and low $\left(14^{\circ} \mathrm{C}\right)$ constant temperatures and the diurnal $(12 \mathrm{~h} / 12 \mathrm{~h})$ by $8^{\circ} \mathrm{C}$ varying counterparts of the same mean $\left(16 / 24^{\circ} \mathrm{C}, 13 / 21^{\circ} \mathrm{C}, 10 / 18^{\circ} \mathrm{C}\right)$. The hatch was observed thoroughly till larval hatch stopped. 


\section{Data analysis}

All statistical tests were performed using Statistica 10 (StatSoft ${ }^{\circledR}$, Tulsa, USA). All data were tested for the normal distribution with the Shapiro-Wilk-test and by visual observation of histograms. Levene's test was carried out to test the equality of variances.

\section{Experiment 1}

Required day-degrees $\left(\mathrm{D}^{\circ}\right)$ (dependent variable) for hatching and hatching rates under different varying temperature regimes (independent variable) and the $25^{\circ} \mathrm{C}$ control regime were tested with a one-way analysis of variance (ANOVA) adjusted with Tukey-Kramer-test. Log-transformed larval dry weights (dependent variable) were used to test for differences in development under the three different regimes (independent variable) on all experimental days (ED), by means of a Kruskal-WallisANOVA (K-W-ANOVA), adjusted with a multiple p-value comparison (two-sided). Temperature-dependent plant growth, grouped by ED, was tested with a one-way ANOVA and adjusted with a Tukey-Kramer-test (TK-test). To separate direct temperature effects (categorical predictor) and indirect effects by plant growth (continuous predictor) on larval weight an analysis of covariance (ANCOVA) for each experimental day was performed. A simple regression was used to quantify the effect of plant height (predictor variable) on WCR log transformed dry weight $(\mu \mathrm{g})$ (dependent variable).

The impact of the different temperature regimes (independent variable) on larval recovery (\%) as dependent variable was tested with the K-W-ANOVA, adjusted with a multiple $\mathrm{p}$-value comparison (two-sided). Correlations between recovery (dependent variable) and plant height (predictor variable) were tested with a simple regression. 


\section{Experiment 2}

The hatching rates (dependent variable) of constant temperature and corresponding varying temperature (temperature regime = grouping variable) were tested pair wise for differences with Mann-Whitney U-test (MWU-test) at five different temperature sums.

Final hatching rates (dependent variable) of all regimes after a temperature sum of $354 D^{\circ}$ were tested for differences with a K-W-ANOVA, adjusted with a multiple $p$ value comparison (two-sided). 


\section{Results}

\section{Experiment 1}

\section{Influence of temperature regimes on egg hatching}

Different varying temperature regimes did not influence the hatching rates of eggs (one-way ANOVA: $P=0.57, F(2,17)=0.59)$, and the hatching rates were not significantly different compared to the $25^{\circ} \mathrm{C}$ constant control regime (one-way ANOVA: $P=0.22, F(3,20)=1.62)$.

The temperature sums larvae required for hatching significantly differed between the three treatments (one-way ANOVA: $P<0.01, F(2,17)=30.85$; Tukey-Kramer-test adjusted). Eggs reared at temperature regimes with varying day-night temperatures hatched at lower temperature sums (Figure 1). $50 \%$ of egg hatching would occur at JD 171 with regard to the $6^{\circ} \mathrm{C}$ difference regime, at JD 175 with regard to the $4^{\circ} \mathrm{C}$ difference regime and at JD 179 with regard to the constant temperature regime (Table 2).

\section{Western corn rootworm larval recovery}

Recovery was not affected by any temperature regime on the different ED (K-WANOVA, adjusted with a multiple $p$-value comparison (two-sided): ED $71 P=0.043$, $H(2, \mathrm{~N}=35)=6.32$, multiple $\mathrm{p}$-value comparison shows no differences; ED 78 $P=0.073, H(2, \mathrm{~N}=35)=5.24$; ED $85 P=0.059, H(2, \mathrm{~N}=35)=5,67$; ED $92 P=0.89, H$ $(2, N=35)=0.25)$, but a simple regression showed slight positive correlations with plant height for experimental day 71,78 and 85 (Table 3). 


\section{Influence of temperature regimes on larval development}

Larval recovery was too low for statistical analyses at the first three extraction dates. The larval development shown as log larval dry weight $(\mu \mathrm{g})$ of extractions from experimental day 71, 78, 85 and 92 (ED 71, ED 78, ED 85 and ED 92), respectively, is mapped in Figure 2. Developmental differences between the regimes changes between the extraction dates.

Larvae kept under varying day-night temperatures with a $4^{\circ} \mathrm{C}$ difference had a lower log larval dry weight $(\mu \mathrm{g})$ on ED 71 than larvae from the $6^{\circ} \mathrm{C}$ difference regime. Larval development under the constant temperature regime did neither differ from the $4^{\circ} \mathrm{C}$ difference regime nor from the $6^{\circ} \mathrm{C}$ difference regime (K-W-ANOVA, adjusted with a multiple $\mathrm{p}$-value comparison (two-sided): $P=0.02, H(2, \mathrm{~N}=24)=7.91)$.

One week later, on ED 78, larvae reared under constant temperatures had a lower weight gain than larvae reared under varying day-night temperatures. The larvae recovered from the $6^{\circ} \mathrm{C}$ difference regime had significant higher larval weights than $4^{\circ} \mathrm{C}$ regime larvae (K-W-ANOVA, adjusted with a multiple $\mathrm{p}$-value comparison (twosided): $P<0.01, \mathrm{H}(2, \mathrm{~N}=32)=16.29)$.

On ED 85 the larval weight differences between the regimes were reduced, but were still significant between the constant temperature and the varying $6^{\circ} \mathrm{C}$ difference regime (K-W-ANOVA, adjusted with a multiple $\mathrm{p}$-value comparison (two- sided): $P<0.01, \mathrm{H}(2, \mathrm{~N}=33)=8.51)$.

On experimental day 92 no detectable differences in larval development between the regimes were detected anymore (K-W-ANOVA: $P=0.37, H(2, \mathrm{~N}=31)=1.99)$. Weight gain did not increase any more at the $6{ }^{\circ} \mathrm{C}$ difference regime compared to experimental day 85 (Figure 2). 


\section{Influence of temperature regimes on plant height}

Plant growth was positively affected by varying temperatures (Figure 3). While at ED 71 no significant differences in plant height were detectable (one-way ANOVA:

$P=0.26, F(2,21)=1,43)$, plant height was positively affected by the varying temperature regimes on ED 78 (one-way ANOVA: $P<0.01, F(2,29)=16.11$; TK-test adjusted) and ED 85 (one-way ANOVA: $P<0.01, F(2,30)=32.46$; TK-test adjusted), plants height increased with increasing day-night differences. At ED 92 only under constant temperature grown plants were significantly smaller than those which were grown under varying temperatures (one-way ANOVA: $P<0.01, F(2,28)=18.84$; TKtest adjusted).

\section{Correlation between plant growth and larval development}

ANCOVA showed that a direct temperature effect on larval development only left at ED 71 and that plant height (covariate) significantly affected WCR-larvae log transformed dry weight $(\mu \mathrm{g})$. Larval development was highly correlated with plant height (Table 4). Regression equations are shown in Table 5. On every experimental day larvae developed faster on higher plants than on smaller plants. 


\section{Experiment 2}

\section{Influence of temperature regimes on egg hatching}

Over the whole experiment the hatching rate courses were higher at the diurnal varying temperature regime as the corresponding constant temperatures (Figure 4). The pair wise comparison of the varying and corresponding constant temperature showed that at varying temperatures a lower temperature sum is needed to reach a certain low level of hatching rate, even though this effect diminish for the high and mediate temperature regime when hatch was almost finished (MWU-test: exact results in Table 6). The final hatching rates between the four temperature regimes with mediate and high development temperature and even the low diurnal varying regime did not differ from each other. Only the constant $14^{\circ} \mathrm{C}$ regime lowers the final hatching rate (K-W-ANOVA, adjusted with a multiple $\mathrm{p}$-value comparison (two-sided): $P=0.000, H(5, \mathrm{~N}=96)=50.53)$. 


\section{Discussion}

In the first experiment western corn rootworm egg and larval development was notably enhanced at varying temperatures compared with development under constant temperatures. As we hypothesized especially hatch, as a fundamental key factor for pest management decisions, occurred considerably earlier at varying temperatures as expected under constant temperatures. In contrast to the assumption of Fisher (1989) the temperature sum necessary for hatch differed between the constant and the varying temperature regimes. Whereas $50 \%$ hatch was at Julian day 179 under constant temperature regime, at the $4^{\circ} \mathrm{C}$-difference regime $50 \%$ hatch occurred at JD 175 and at the $6^{\circ} \mathrm{C}$-difference regime at JD 171.

This finding contradicts studies which report retarded development (Hagstrum \& Hagstrum 1970; Clarkson, Hobischak, \& Anderson 2004; Siegel, Bas Kuenen, \& Ledbetter 2010) or no influence (Hagstrum \& Leach 1973; Humpesch 1982) of varying temperatures on insect development, but is accordant to prior studies (Hagstrum \& Hagstrum 1970; Behrens et al. 1983; Roltsch, Mayse, \& Clausen 1990; Blanckenhorn 1997; Bryant, Bale, \& Thomas 1999) where insect development was enhanced at the varying temperature regimes. One explanation for this enhanced development rate is provided by the Kaufmann-effect, also known as rate summation. The "law of effective temperatures" which measures the species specific physiological time to complete a developmental stage (thermal constant) in degreedays $\left(D^{\circ}\right)$ presume a linear relationship between the temperature and the development rate (Damos \& Savopoulou-Soultani 2012), but the relationship of temperature and the development rate is not linear over the whole temperature range between lower- and upper threshold of development, instead of that the development-temperature relationship can be pictured as a logistic curve (Kaufmann 1932). In the range of the logistic curve, where temperature and development rate have a linear relationship, the temperature sum to reach a developmental stage (like hatch) is identical under varying and adequate constant mean temperatures. When the development temperatures come near or fall below the lower threshold of development, a varying temperature accelerates the development rate and the development will be completed at a lower temperature sum, this effect is visible at the low temperature regime at Experiment 2. At the varying low temperature of 10 / $18^{\circ} \mathrm{C}$ a significant lower amount of accumulated day-degrees was necessary for hatch than the corresponding constant temperature $\left(14^{\circ} \mathrm{C}\right)$ and all higher 
temperature. When the development temperature is near the upper threshold of development, a higher amount of day-degrees is necessary for the completion of the development under varying temperatures than predicted under constant temperatures.

Additionally, the fact that direct temperature effects in the first experiment were exclusively related to the time and temperature sum of hatch (Figure 1) which occurs under relatively low temperatures near the threshold of development and that hatch affected early larval development (ED 71), but diminished on later extraction dates with higher temperatures (Table 4) indicate the Kaufmann-effect as conclusive explanation. On the other hand approximation of development between the regimes on late extraction dates (ED 85 and 92) can be related to an early reached (ED 78) maximal weight of $6^{\circ} \mathrm{C}$-difference regime larvae while larvae development of the other regimes decelerated (Figure 2). An additional explanation for the accelerated development under varying temperatures would be a potentially circadian feeding behaviour (Miyashita 1971; Behrens et al. 1983) of WCR-larvae as adaptation to naturally varying temperatures, gas proportions or humidity conditions. In this case higher day temperatures would enhance development supplementally (Neumann \& Heimbach 1975). As it is challenging to observe the behaviour of soil dwelling insects directly (Brown \& Gange 1990), there is yet no study available if larval behaviour of western corn rootworm changes during the day. Influence of biochemical processes on insect life which are dependent on higher temperatures like effectiveness of enzymes, proteins or hormones are discussed by some authors (Sharpe \& DeMichele 1977; Cohet \& David 1978; Beck 1983; Brakefield \& Mazzotta 1995). The day-night temperature changes of $4^{\circ} \mathrm{C}$ and $6^{\circ} \mathrm{C}$ (respectively $8^{\circ} \mathrm{C}$ ) used in this study can be regarded as moderate, as Petavy (Petavy et al. 2001) assumed daily fluctuations of $10^{\circ} \mathrm{C}$ and more for most terrestrial life.

Plant growth and chemical composition are as well highly temperature affected (Went 1953; Leather 2010). Varying temperatures extensively enhanced plant growth in this experiment. Plant growth was limited in the climate cabinets, due to the distance between the pots and the lamps which was $70 \mathrm{~cm}$ and plant reached at ED 78 under the $6^{\circ} \mathrm{C}$-temperature regime while the other plants approximated to this value during the experiment (Figure 3). The quality (Awmack \& Leather 2002) and quantity of available adequate host biomass are essential factors for herbivores; hence here larval development (Table 5) and recovery (Table 3) were highly positive correlated 
with well grown plants.

The lack of preferred bigger newly grown nodal roots (Hibbard et al. 2008) or starvation due to the lack of sufficient root biomass (Musick et al. 1980) slowed larval development down on small plants compared to bigger plants of the same age (Bergman \& Turpin 1984).

Our method is useful to observe early development under accurately controlled conditions. To optimise prediction of WCR hatch in the field further studies with various varying temperatures should be done for egg development and hatching patterns of different European WCR-strains. This is because they might differ from the US-non-diapausing laboratory strain, as US-strains differ from each other (Levine, Oloumi-Sadeghi, \& Ellis 1992) and in Europe at least 5 different introductions from origin populations occurred (Ciosi et al. 2008). 


\section{References}

Awmack, C.S. \& Leather, S.R. (2002) Host plant quality and fecundity in herbivorous insects. Annual Review of Entomology, 47, 817-844.

Beck, S.D. (1983) Thermal and thermoperiodic effects on larval development and diapause in the European corn borer, Ostrinia nubilalis. Journal of Insect Physiology, 29, 107-112.

Behrens, W., Hoffmann, K.-H., Kempa, S., Gäßler, S. \& Merkel-Wallner, G. (1983) Effects of diurnal thermoperiods and quickly oscillating temperatures on the development and reproduction of crickets, Gryllus bimaculatus. Oecologia, 59, 279-287.

Bergant, K. \& Trdan, S. (2006) How reliable are thermal constants for insect development when estimated from laboratory experiments? Entomologia Experimentalis et Applicata, 120, 251-256.

Bergman, M.K. \& Turpin, F.T. (1984) Impact of corn planting date on the population dynamics of corn rootworms (Coleoptera: Chrysomelidae). Environmental Entomology, 13, 898-901.

Blanckenhorn, W.U. (1997) Effects of temperature on growth, development and diapause in the yellow dung fly: against all the rules? Oecologia, 111, 318324.

Brakefield, P.M. \& Mazzotta, V. (1995) Matching field and laboratory environments: effects of neglecting daily temperature variation on insect reaction norms. Journal of Evolutionary Biology, 8, 559-573.

Branson, T.F. (1976) The selection of a non-diapause strain of Diabrotica virgifera (Coleoptera: Chrysomelidae). Entomologia Experimentalis et Applicata, 19, 148-154.

Brown, V.K. \& Gange, A.C. (1990) Insect herbivory insect below ground. Advances in Ecological Research pp. 1-58. Academic Press.

Bryant, S.R., Bale, J.S. \& Thomas, C.D. (1999) Comparison of development and growth of nettle-feeding larvae of Nymphalidae (Lepidoptera) under constant and alternating temperature regimes. European Journal of Entomology, 96, 143-148.

Ciosi, M., Miller, N.J., Kim, K.S., Giordano, R., Estoup, A. \& Guillemaud, T. (2008) Invasion of Europe by the western corn rootworm, Diabrotica virgifera virgifera: multiple transatlantic introductions with various reductions of genetic diversity. Molecular Ecology, 17, 3614-3627.

Clarkson, C.A., Hobischak, N.R. \& Anderson, G.S. (2004) A comparison of the development rate of Protophormia terraenovae (Robineau-Desvoidy) raised under constant and fluctuating temperature regimes. Canadian Society of Forensic Sciences Journal, 37, 95-101. 
Cohet, Y. \& David, J. (1978) Control of the adult reproductive potential by preimaginal thermal conditions. Oecologia, 36, 295-306.

Damos, P. \& Savopoulou-Soultani, M. (2012) Temperature-driven models for insect development and vital thermal requirements. Psyche: A Journal of Entomology, 2012, 1-13.

EPPO. (2011) Diabrotica virgifera, http://www.eppo.org/QUARANTINE/Diabrotica_virgifera/diabrotica_virgifera.ht $\mathrm{m}$

Fisher, J.R. (1989) Hatch of Diabrotica virgifera virgifera (Coleoptera: Chrysomelidae) eggs exposed to two different overwintering and hatch regimes. Journal of the Kansas Entomological Society, 62, 607-610.

Gray, M.E., Sappington, T.W., Miller, N.J., Moeser, J. \& Bohn, M.O. (2009) Adaptation and invasiveness of western corn rootworm: intensifying research on a worsening pest. Annual Review of Entomology, 54, 303-321.

Hagstrum, W.R. \& Hagstrum, D.W. (1970) A simple device for producing fluctuating temperatures, with an evaluation of the ecological significance of fluctuating temperatures. Annals of the Entomological Society of America, 63, 13851389.

Hagstrum, D.W. \& Leach, C.E. (1973) Role of constant and fluctuating Temperatures in determining development time and fecundity of three species of storedproducts Coleoptera. Annals of the Entomological Society of America, 66, 407-410.

Hammack, L., Ellsbury, M.M., Roehrdanz, R.L. \& Pikul, J.L. (2003) Larval sampling and instar determination in field populations of northern and western corn rootworm (Coleoptera: Chrysomelidae). Journal of Economic Entomology, 96, 1153-1159.

Hibbard, B.E., Schweikert, Y.M., Higdon, M.L. \& Ellersieck, M.R. (2008) Maize phenology affects establishment, damage, and development of the western corn rootworm (Coleoptera: Chrysomelidae). Environmental Entomology, 37, 1558-1564.

Howe, R.W. (1967) Temperature effects on embryonic development in insects. Annual Review of Entomology, 12, 15-42.

Humpesch, U.H. (1982) Effect of fluctuating temperature on the duration of embryonic development in two Ecdyonurus spp. and Rhithrogena cf. hybrida (Ephemeroptera) from Austrian streams. Oecologia, 55, 285-288.

Jackson, J.J. \& Elliott, N.C. (1988) Temperature-dependent development of immature stages of the western corn rootworm, Diabrotica virgifera virgifera (Coleoptera: Chrysomelidae). Environmental Entomology, 17, 166-171.

Kahler, A., Olness, A., Sutter, G., Dybing, C. \& Devine, O. (1985) Root damage by western corn rootworm and nutrient content in maize. Agron. J, 77, 769-774. 
Kaufmann, O. (1932) Einige Bemerkungen über den Einfluss von Temperaturschwankungen auf die Entwicklungsdauer und Streuung bei Insekten und seine graphische Darstellung durch Kettenlinie und Hyperbel. Zeitschrift für Morphologie und Ökologie der Tiere, 25, 353-361.

Kempson, D., Lloyd, M. \& Ghelardi, R. (1963) A new extractor for woodland litter. Pedobiologia, 3, 1-21.

Kuhlman, D.E., Howe, W.L. \& Luckmann, W.H. (1970) Development of immature stages of the western corn rootworm at varied temperatures. Proceedings of the North Central Branch Entomological Society of America, 25, 93-95.

Lancashire, P.D., Bleiholder, H., Boom, T. van den, Langelüddeke, P., Stauss, R., Weber, E. \& Witzenberger, A. (1991) A uniform decimal code for growth stages of crops and weeds. Annals of Applied Biology, 119, 561-601.

Leather, S.R. (2010) Precise knowledge of plant growth stages enhances applied and pure research. Annals of Applied Biology, 157, 159-161.

Levine, E., Oloumi-Sadeghi, H. \& Ellis, C.R. (1992) Thermal requirements, hatching patterns, and prolonged diapause in western corn rootworm (Coleoptera: Chrysomelidae) Eggs. Journal of Economic Entomology, 85, 2425-2432.

Liu, S.-S., Zhang, G.-M. \& Zhu, J. (1995) Influence of temperature variations on rate of development in insects: analysis of case studies from entomological literature. Annals of the Entomological Society of America, 88, 107-119.

Miyashita, K. (1971) Effects of constant and alternating temperatures on the development of Spodoptera litura F.: Lepidoptera: Noctuidae. Applied entomology and zoology, 6, 105-111.

Musick, G.J., Chiang, H.C., Luckmann, W.H., Mayo, Z.B. \& Turpin, F.T. (1980) Impact of planting dates of field corn on beetle emergence and damage by the western and the northern corn rootworms in the Corn Belt. Annals of the Entomological Society of America, 73, 207-215.

Neumann, D. \& Heimbach, F. (1975) Das Wachstum des Kohlweißlings bei konstanten und tagesperiodisch wechselnden Temperaturen. Oecologia, 20, 135-141.

Petavy, David, J.R., Gibert, P. \& Moreteau, B. (2001) Viability and rate of development at different temperatures in Drosophila: a comparison of constant and alternating thermal regimes. Journal of Thermal Biology, 26, 29-39.

Riedell, W.E. (1990) Rootworm and mechanical damage effects on root morphology and water relations in maize. Crop Science, 30, 628.

Roltsch, W.J., Mayse, M.A. \& Clausen, K. (1990) Temperature-dependent development under constant and fluctuating temperatures: comparison of linear versus nonlinear methods for modeling development of western grapeleaf skeletonizer (Lepidoptera: Zygaenidae). Environmental Entomology, 19, 1689-1697. 
Schaafsma, A.W., Baufeld, P. \& Ellis, C.R. (1999) Influence of cropping practices on corn rootworm in Canada as a basis for assessment of the potential impact of Diabrotica virgifera in Germany. EPPO Bulletin, 29, 145-154.

Schaafsma, A.W., Whitfield, G.H. \& Ellis, C.R. (1991) A temperature-dependent model of egg development of the Western Corn Rootworm, Diabrotica virgifera virgifera LeConte (Coleoptera: Chrysomelidae). The Canadian Entomologist, 123, 1183-1197.

Sharpe, P.J.H. \& DeMichele, D.W. (1977) Reaction kinetics of poikilotherm development. Journal of Theoretical Biology, 64, 649-670.

Siegel, J.P., Bas Kuenen, L.P.S. \& Ledbetter, C. (2010) Variable development rate and survival of navel orangeworm (Lepidoptera: Pyralidae) on wheat bran diet and almonds. Journal of Economic Entomology, 103, 1250-1257.

Spencer, J.L., Hibbard, B.E., Moeser, J. \& Onstad, D.W. (2009) Behaviour and ecology of the western corn rootworm (Diabrotica virgifera virgifera LeConte). Agricultural and Forest Entomology, 11, 9-27.

Szalai, M., Papp Komáromi, J., Bažok, R., Igrc Barčić, J., Kiss, J. \& Toepfer, S. (2010) Generational growth rate estimates of Diabrotica virgifera virgifera populations (Coleoptera: Chrysomelidae). Journal of Pest Science, 84, 133142.

Went, F.W. (1953) The effect of temperature on plant growth. Annual Review of Plant Physiology, 4, 347-362.

Wesseler, J. \& Fall, E.H. (2010) Potential damage costs of Diabrotica virgifera virgifera infestation in Europe - the 'no control' Scenario. , 134, 385-394.

Wilde, G.E. (1971) Temperature effect on development of western corn rootworm eggs. Journal of the Kansas Entomological Society, 44, 185-187. 


\section{Annex}

\section{$\underline{\text { Tables }}$}

\section{Experiment 1}

Table 1: weekly adjusted experimental mean temperatures calculated from historical (19712000) data from the DWD (Deutscher Wetterdienst) in Lingen. Julian Day 121 is experimental day 1 and corresponds to the 1 . May in the field

\begin{tabular}{cc} 
Julian Day & $\mathrm{T}(\mathrm{mean})\left({ }^{\circ} \mathrm{C}\right)$ \\
\hline $121-127$ & 11.4 \\
$128-134$ & 12.8 \\
$135-141$ & 13.9 \\
$142-148$ & 13.9 \\
$149-155$ & 14.9 \\
$156-162$ & 15.4 \\
$163-169$ & 15.5 \\
$170-176$ & 15.5 \\
$177-183$ & 16.5 \\
$184-190$ & 17.9 \\
$191-197$ & 17.7 \\
$198-204$ & 17.2 \\
$205-211$ & 17.9 \\
$212-218$ & 18.6 \\
\hline
\end{tabular}

Table 2: Julian days for $50 \%$ hatch (JD $50 \%$ ), first larval hatch (JD min), hatch of last larva (JD max) and standard deviation (SD) in the hatch tests $\left(N_{0}=4 ; N_{4}=8 ; N_{6}=8\right)$.

\begin{tabular}{ccccc} 
temperature difference & JD 50\% hatch & JD min & JD max & SD \\
\hline 0 & 178.8 & 171 & 186 & 3.5 \\
4 & 174.9 & 167 & 188 & 4.2 \\
6 & 170.5 & 163 & 184 & 3.6 \\
\hline
\end{tabular}


Table 3: Regression equations of plant height $(\mathrm{cm})$ as predictor and larval recovery $(\%)$ as dependent variable at experimental days $71,78,85$ and 92

\begin{tabular}{ccccc}
$\begin{array}{c}\text { Experimental } \\
\text { day }\end{array}$ & recovery (\%):plant height $(\mathrm{cm})$ & $F$ & $P$ & $R^{2}$ \\
\hline 71 & $\mathrm{y}=40.49+0.32^{*} \mathrm{x}$ & 5.94 & 0.02 & 0.16 \\
78 & $\mathrm{y}=45.15+0.26^{*} \mathrm{x}$ & 9.42 & $<0.01$ & 0.23 \\
85 & $\mathrm{y}=46.65+0.22^{*} \mathrm{x}$ & 6.94 & 0.01 & 0.18 \\
92 & $\mathrm{y}=49.85+0.18^{*} \mathrm{x}$ & 1.48 & n. s. & 0.05 \\
\hline
\end{tabular}

Table 4: Significance of plant height $(\mathrm{cm})$ as covariate and day-night temperature difference on western corn rootworm log larval dry weight $(\mu \mathrm{g})$ at experimental days $71,78,85$ and 92 analysed with analysis of covariance (ANCOVA; $n$. s.: $P>0.05$ )

\begin{tabular}{ccrrr}
$\begin{array}{c}\text { Experimental } \\
\text { day }\end{array}$ & variable & $F$ & df & $P$ \\
\hline 71 & plant height $(\mathrm{cm})$ & 17.12 & 1 & $<0.01$ \\
& day-night temperature difference $\left({ }^{\circ} \mathrm{C}\right)$ & 5.84 & 2 & 0.01 \\
78 & plant height $(\mathrm{cm})$ & 10.28 & 1 & $<0.01$ \\
& day-night temperature difference $\left({ }^{\circ} \mathrm{C}\right)$ & 2.95 & 2 & $\mathrm{n} . \mathrm{s}$. \\
85 & plant height $(\mathrm{cm})$ & 13.09 & 1 & $<0.01$ \\
& day-night temperature difference $\left({ }^{\circ} \mathrm{C}\right)$ & 0.21 & 2 & $\mathrm{n} . \mathrm{s}$. \\
92 & plant height $(\mathrm{cm})$ & 12.52 & 1 & $<0.01$ \\
& day-night temperature difference $\left({ }^{\circ} \mathrm{C}\right)$ & 0.81 & 2 & n. s. \\
\hline
\end{tabular}

Table 5: Regression equations of plant height $(\mathrm{cm})$ as predictor and log larval dry weight $(\mu \mathrm{g})$ as dependent variable at experimental days $71,78,85$ and 92

\begin{tabular}{ccccc}
$\begin{array}{c}\text { Experimental } \\
\text { day }\end{array}$ & $\begin{array}{c}\text { log }(\text { larval dry weight }(\mu \mathrm{g})): \\
\text { plant height }(\mathrm{cm})\end{array}$ & $F$ & $P$ & $R^{2}$ \\
\hline 71 & $\mathrm{y}=22.58+18.31^{*} \mathrm{x}$ & 14.02 & $<0.01$ & 0.39 \\
78 & $\mathrm{y}=1.87+27.87^{*} \mathrm{x}$ & 45.33 & $<0.01$ & 0.60 \\
85 & $\mathrm{y}=0.67+26.51^{*} \mathrm{x}$ & 33.10 & $<0.01$ & 0.52 \\
92 & $\mathrm{y}=3.90+23.94^{*} \mathrm{x}$ & 15.72 & $<0.01$ & 0.35 \\
\hline
\end{tabular}




\section{Experiment 2}

Table 6: The hatching rates (dependent variable) of constant temperature and corresponding varying temperature (temperature regime $=$ grouping variable) for the high $\left(20^{\circ} \mathrm{C} ; 16 / 24^{\circ} \mathrm{C}\right.$ ), mediate $\left(17^{\circ} \mathrm{C} ; 13 / 21^{\circ} \mathrm{C}\right)$ and low $\left(14^{\circ} \mathrm{C} ; 10 / 18^{\circ} \mathrm{C}\right)$ temperature regimes, pair wise tested for differences with Mann-Whitney U-test at five different temperature sums (the asterisk marks significant differences; $N_{\text {varying }}=16 ; N_{\text {constant }}=16$ ).

\begin{tabular}{|c|c|c|c|c|}
\hline temperature regime & temperature sum $\left(\mathrm{D}^{\circ}\right)$ & $U$ & $Z$ & $P$ \\
\hline \multirow{5}{*}{$20^{\circ} \mathrm{C} ; 16 / 24^{\circ} \mathrm{C}$} & 198 & 55.00 & -2.75 & $<0.01$ \\
\hline & 216 & 50.00 & -2.92 & $<0.01$ \\
\hline & 252 & 118.50 & -0.34 & 0.73 \\
\hline & 330 & 127.00 & 0.02 & 0.98 \\
\hline & 354 & 127.00 & 0.02 & 0.98 \\
\hline \multirow{5}{*}{$17^{\circ} \mathrm{C} ; 13 / 21^{\circ} \mathrm{C}$} & 198 & 8,00 & -4.88 & $<0.01$ \\
\hline & 216 & 0,00 & -4.81 & $<0.01$ \\
\hline & 252 & 55,00 & -2.73 & $<0.01$ \\
\hline & 330 & 102,00 & -0.96 & 0.34 \\
\hline & 354 & 103,00 & -0.92 & 0.36 \\
\hline \multirow{5}{*}{$14^{\circ} \mathrm{C} ; 10 / 18^{\circ} \mathrm{C}$} & 198 & 0,00 & -4.91 & $<0.01$ \\
\hline & 216 & 0,00 & -4.81 & $<0.01$ \\
\hline & 252 & 2,00 & -4.73 & $<0.01$ \\
\hline & 330 & 2,00 & -4.73 & $<0.01$ \\
\hline & 354 & 2,00 & -4.73 & $<0.01$ \\
\hline
\end{tabular}


$\underline{\text { Figures }}$

\section{Experiment 1}

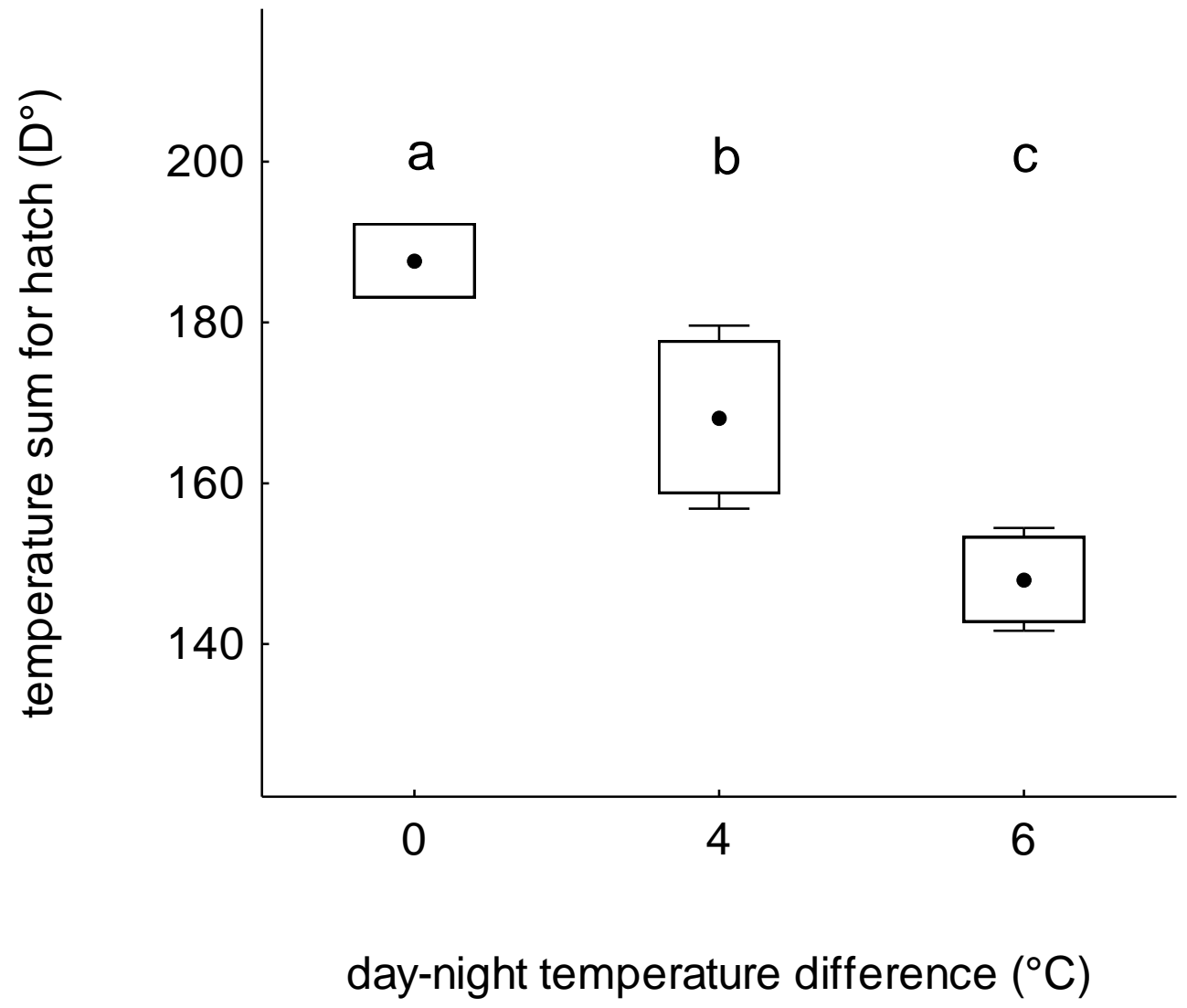

Figure 1: Temperature sum in day-degrees $\left(D^{\circ}\right)$ for a base temperature of $11^{\circ} \mathrm{C}$ required for larval hatch at temperature regimes with constant $(0)$, varying day-night temperature with differences of $4^{\circ} \mathrm{C}(4)$ and $6^{\circ} \mathrm{C}(6)$ (ANOVA, Tukey-Kramer-test adjustment; dot = mean, box = mean $\pm 0.95 \mathrm{Cl}$, whisker $=$ mean $\pm \mathrm{SD}$; letters indicate significant statistical differences; hatch tests $N_{0}=4 ; N_{4}=8 ; N_{6}=8$ ). 
A)

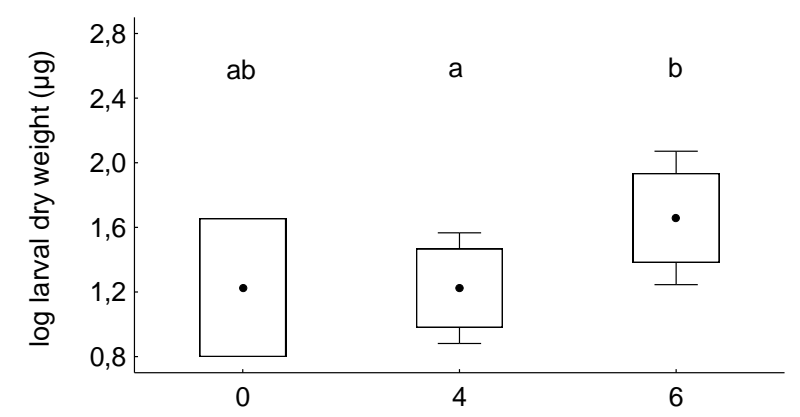

C)

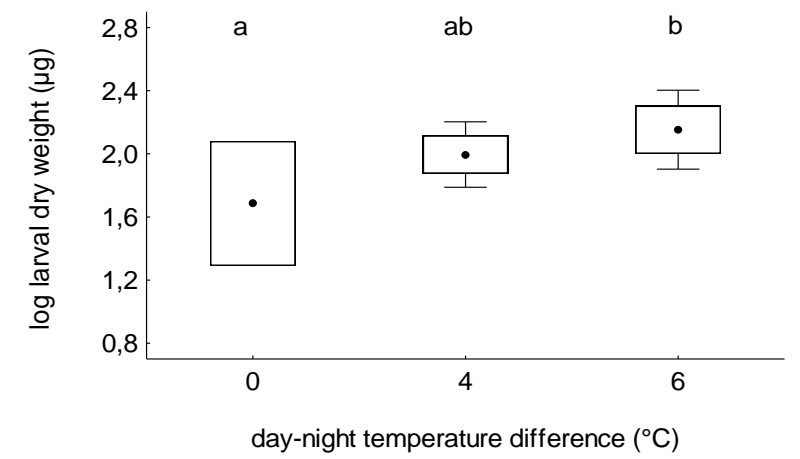

B)

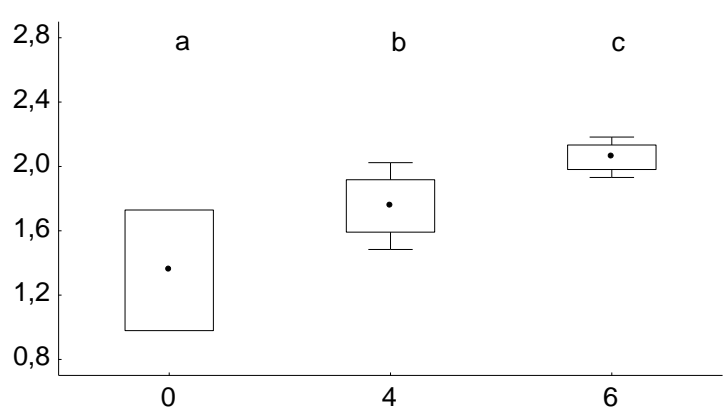

D)

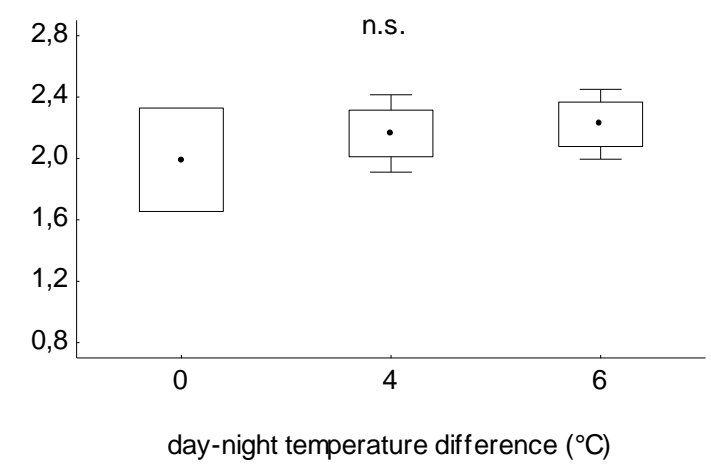

Figure 2: Compared larval development log larval dry weight $(\mu \mathrm{g})$ at all experimental days $(A=$ $\mathrm{ED} 71, \mathrm{~B}=\mathrm{ED} 78, \mathrm{C}=\mathrm{ED} 85, \mathrm{D}=\mathrm{ED}$ 92) at temperature regimes with constant (0), varying daynight temperature with differences of $4^{\circ} \mathrm{C}(4)$ and $6^{\circ} \mathrm{C}(6)$ (Kruskal-Wallis-ANOVA; dot = mean, box $=$ mean $\pm 0.95 \mathrm{Cl}$, whisker $=$ mean $\pm \mathrm{SD}$; letters indicate significant statistical differences; replicates = plants: $N_{0}=7 ; N_{4}=14 ; N_{6}=14$ on every extraction date). 
A)

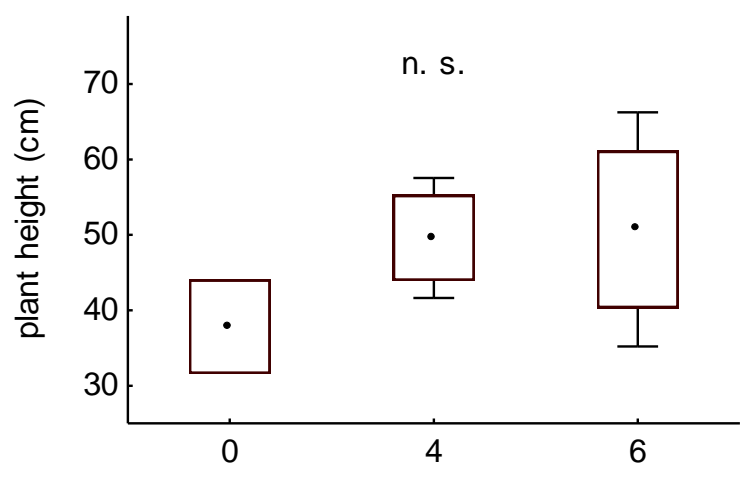

C)

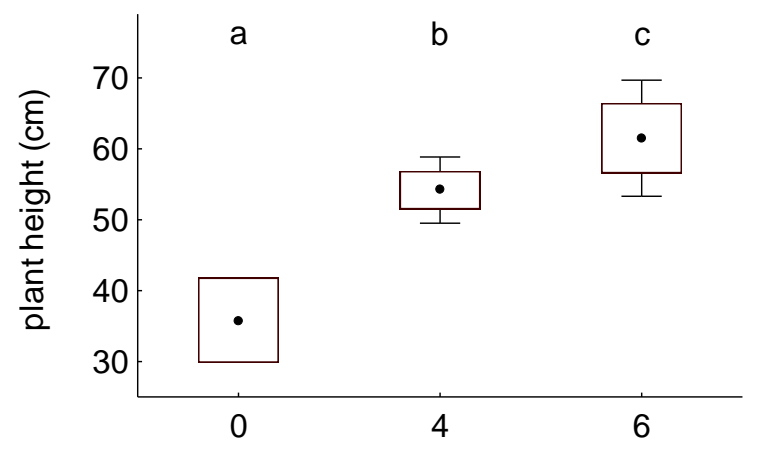

day-night temperature difference $\left({ }^{\circ} \mathrm{C}\right)$
B)

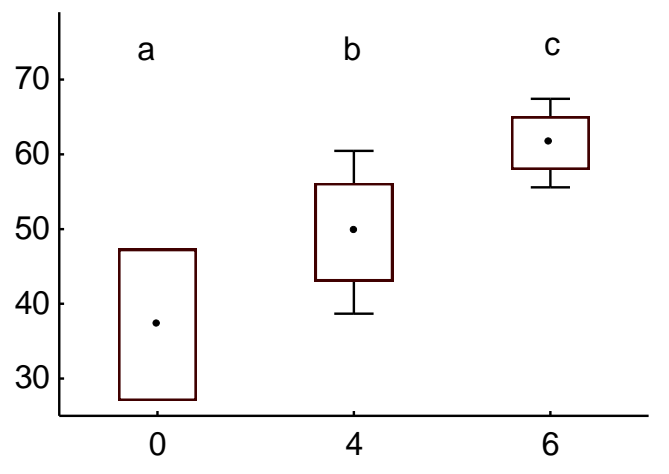

D)

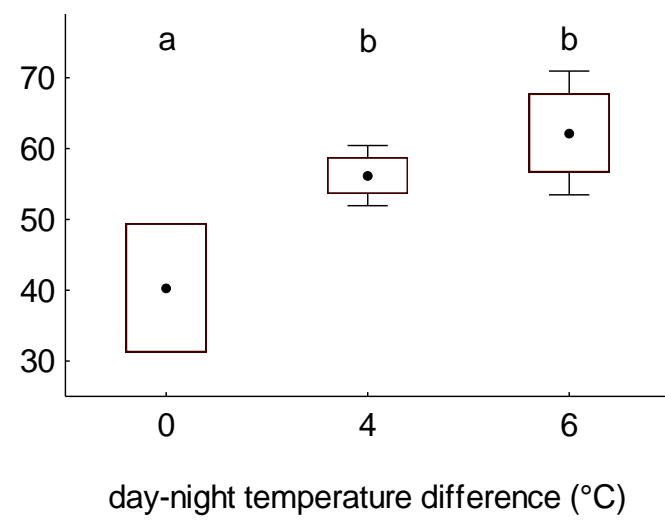

Figure 3: Plant height (cm) at all experimental days ( $A=E D 71, B=E D ~ 78, C=E D ~ 85, ~ D=E D ~ 92)$ at temperature regimes with constant $(0)$, varying day-night temperature with differences of $4^{\circ} \mathrm{C}$ (4) and $6^{\circ} \mathrm{C}$ (6) (ANOVA, Tukey-Kramer-test adjustment; dot = mean, box = mean $\pm 0.95 \mathrm{Cl}$, whisker = mean $\pm \mathrm{SD}$; letters indicate significant statistical differences; $n$. s. = not significant: $P$ $>0.05$; replicates $=$ plants: $N_{0}=7 ; N_{4}=14 ; N_{6}=14$ on every extraction date). 


\section{Experiment 2}

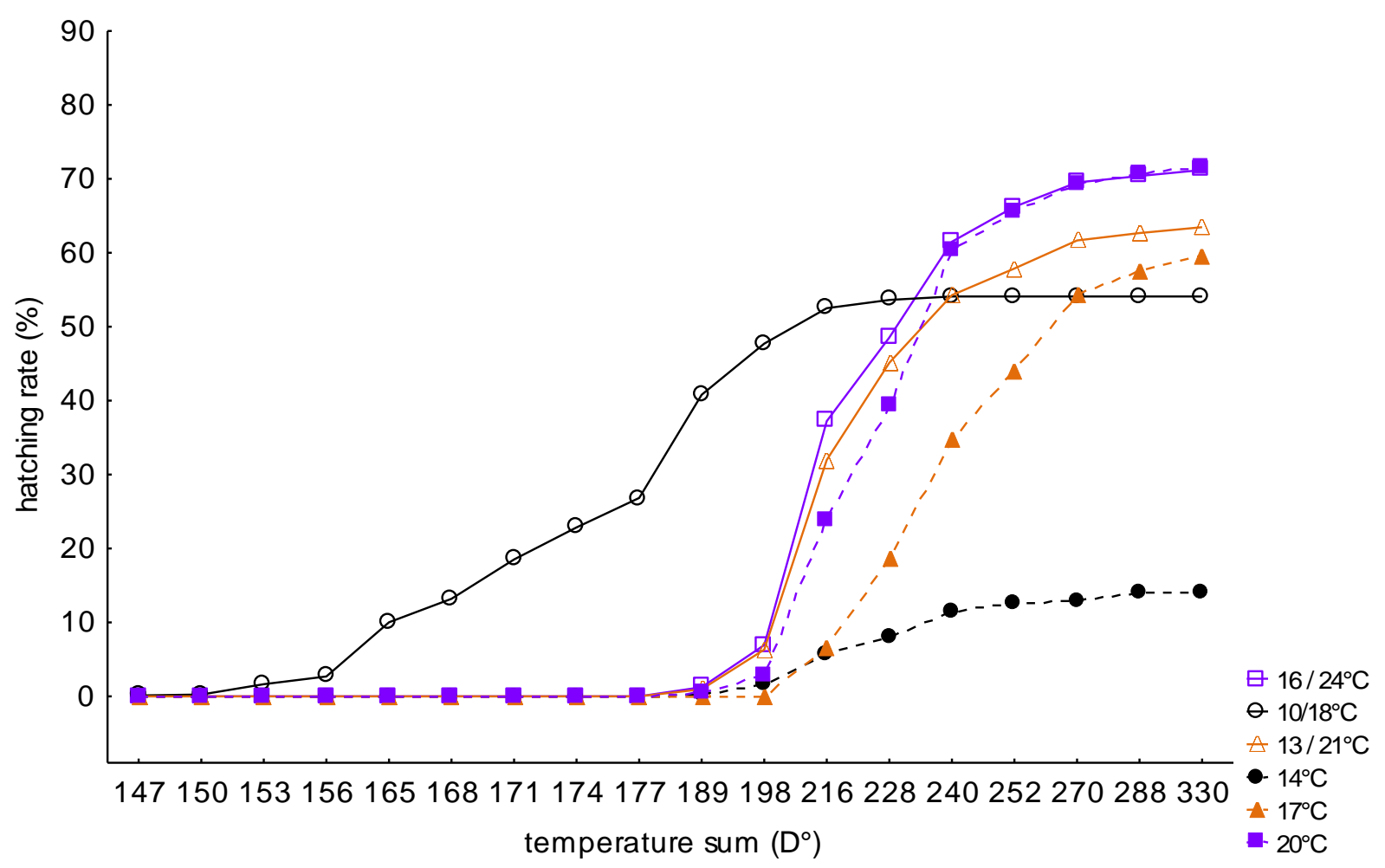

Figure 4: The courses of mean (from each 16 hatch tests) hatching rates of constant temperature (filled emblem) and corresponding varying temperature (empty emblem) for the high $\left(20^{\circ} \mathrm{C} ; 16 / 24^{\circ} \mathrm{C}\right)$, mediate $\left(17^{\circ} \mathrm{C} ; 13 / 21^{\circ} \mathrm{C}\right)$ and low $\left(14^{\circ} \mathrm{C} ; 10 / 18^{\circ} \mathrm{C}\right)$ temperature regimes. 
Development of two different European western corn rootworm (Diabrotica virgifera virgifera LeConte) populations compared with the US non-diapausing laboratory population under a Northern German temperature regime

\section{Abstract}

Separated populations within one species typically differ with regard to their abilities and reactions on environmental impacts addicted to their special habitat. Insects reared in the laboratory additionally are mostly subjected to a loss of genetic diversity. In this study three populations of the western corn rootworm (WCR), an invasive maize pest in Europe, were tested for developmental differences in climate cabinets. We compared the US non-diapausing population, an established agent for WCR research, with two European field populations from Hungary and Serbia. Even if it is known that the laboratory population shows a loss of genetic diversity and differs genetically more from US field populations, than field populations with a high geographical range differs from each other, we could only detect a slight difference in thermal requirements for hatching between laboratory and the field populations. Hungarian population needed about $30 \mathrm{D}^{\circ}$ (degree-days) more for hatch than the laboratory population did. Serbian population showed an intermediate thermal requirement for hatch. The differences between the two field populations indicate rapid adaptation processes of the introduced populations. We found a high impact of plant growth on larval development, with a higher larval dry weight on higher plants. 


\section{Introduction}

Western corn rootworm (Diabrotica virgifera virgifera LeConte, Galerucinae, Chrysomelidae; WCR) is a maize pest native to Central America (Melhus, Painter, \& Smith 1954) and has spread over North America from the mid of $19^{\text {th }}$ century till today (Gray et al. 2009). WCR shows a high adaptability to pest management like crop rotation (Levine et al. 2002) and also evolved resistance to some insecticides (Meinke et al. 1998; Wright et al. 2000). WCR populations in the USA vary in relation to temperature requirements. The threshold of development is reported as $11^{\circ} \mathrm{C}$ for South Dakota (James R. Fisher 1989), Michigan (Ruppel, Russell, \& Jennings 1978) and New York population (Davis, Brenes, \& Allee 1996), $11^{\circ} \mathrm{C}$ or $11.1^{\circ} \mathrm{C}$ for the Minnesota population (Wilde 1971), 12.7 for the Illinois population (Levine, OloumiSadeghi, \& Ellis 1992) and $12.8^{\circ} \mathrm{C}$ for the Kansas population (Chiang 1973). Wilde et al. 1972 showed that the populations from the North of the US from South Dakota and Minnesota need less thermal energy then the more southern populations from lowa, Kansa, Missouri and Nebraska. Higher thermal requirements for hatch were reported from the Illinois population compared to the Minnesota and South Dakota populations (Levine, Oloumi-Sadeghi, \& Ellis 1992). Genetic differences between the US populations are low, but positive correlated with geographic distance (Kim \& Sappington 2005).

Since the late 70 s or early 80 s of the $20^{\text {th }}$ century (Szalai et al. 2010) at least 5 independent introductions from North America into Europe occurred (Ciosi et al. 2008a). There is a high probability that different beetles from source populations with different abilities and adaptations could establish in Europe (Sappington, Siegfried, \& Guillemaud 2006). In 2010 this pest has already been reported from more than 20 European countries (EPPO 2011). When the WCR has established in most maize growing regions in Europe damage costs from more than 470 million Euros per year are expected (Wesseler \& Fall 2010). To model and predict WCR hatch for effective management, hatch, larval development and adult occurrence in the field in Europe should be determined experimentally under regionally climate conditions. A US nondiapausing laboratory population (Branson 1976) is commonly used by many researchers because it is easily available in high numbers, has a short generation time and can be used independently from season. Certainly the US non-diapausing population shows a loss of genetic diversity and differs genetically more from US field populations, than four field populations with a high geographical range differ from 
each other (Kim et al. 2007).

In this study we tested whether the US non-diapausing laboratory population is an adequate organism to study WCR development in Europe. Therefore in our experiment the US non-diapausing population was tested for differences to two European field populations from Serbia and Hungary with regard to (i) the required thermal energy for hatch, (ii) their hatching rate, (iii) larval development and (iv) recovery rate under a simulated Northern German temperature regime.

We hypothesize that there is a difference between the populations with regard to their temperature requirements. 


\section{Material and Methods}

The maize seeds were pregerminated for $24 \mathrm{~h}$ on moistened filter paper at $25^{\circ} \mathrm{C}$ (cultivar Susann, Saaten Union, Germany) and were sown individually in $3 \mathrm{~cm}$ depth into pots (13cm diameter) with Haplic Luvisol (sand/ silt/ clay-content: 3.0\% / 55.2\% / 41.8\%; $\mathrm{pH}\left(\mathrm{H}_{2} \mathrm{O}\right)$ 7.6; C/N-ratio 15.8) from a field near Goettingen. The soil was homogenized with a soil shredder (Unifix 300, Moeschle, Ortenberg, Germany). Eggs from three different WCR-populations were used in this experiment: the nondiapausing WCR laboratory population (USDA-ARS, North Central Agricultural Research Laboratory, Brookings, North Dakota, USA (Branson 1976)), one Serbian population collected from a field near Kula in the year 2009 and one Hungarian population from a field near Dalmand also collected in 2009. In the fields adults were caught, egg laying occurred in the laboratory. All eggs were stored below $8^{\circ} \mathrm{C}$ until their use.

Eggs were washed with a sieve $(250 \mu \mathrm{m})$ from soil and added to a sterile $0.15 \%$ agar solution. Each plant was infested with 50 viable eggs using a pipette (Multipipette Plus, Eppendorf, Hamburg, Germany) into the soil at a depth of $7 \mathrm{~cm}$. To monitor hatching rate and hatching date, hatch tests were prepared. $1 \mathrm{ml}$ of egg solution was added into Petri dishes with sterile moistened filter paper. 2 randomly chosen Petri dishes per cabinet from the field populations and one from the US population were reared under experimental conditions and 2 Petri dishes from each population were placed into an incubator with constant $25^{\circ} \mathrm{C}$ at $60 \% \mathrm{RH}$ to observe hatching patterns. The eggs were counted and checked daily for hatching.

16 infested plants (6 with Hungarian, 6 with Serbian, 4 with US eggs) per cabinet were randomly placed into 3 climate cabinets (Mytron WB 750 KFL, Mytron Bio- und Solartechnik GmbH, Heiligenstadt, Germany) with by data logger (Voltcraft DL-120 TH, Conrad Electronic SE, Hirschau, Germany) controlled and adjusted weekly mean temperatures. Meteorological data compiled by the DWD (Deutscher Wetterdienst), comprising the period between 1971 to 2000 at the location of Lingen were used to calculate weekly adjusted mean temperatures in Northern Germany (Table 1). Lingen was chosen because of its location in a high risk area for an establishment of high WCR populations and thus heavy damage potential (Schaafsma, Whitfield, \& Ellis 1991) because of high frequencies of continuous maize. Temperature regime of Lingen was established starting from Julian day 121 as the sowing date and the first mean temperature above the base temperature of $11^{\circ} \mathrm{C}$ as the threshold of WCR 
development. Relative humidity was adjusted to $60 \% \pm 5 \%$ and the photoperiod was 16h: 8h (light: darkness). The Experiment ended at Julian Date 212 at a temperature sum of 402 day-degrees $\left(D^{\circ}\right)$ for a base temperature of $11^{\circ} \mathrm{C}$. Plant height was measured and larvae were extracted from soil using a high gradient Kempson device (Kempson, Lloyd, \& Ghelardi 1963) for 2 days at $60^{\circ} \mathrm{C}$. Larvae were counted and head capsule width was measured using a binocular microscope with integrated object micrometer to determine larval instar (Hammack et al. 2003). Thereafter larvae were dried at $60^{\circ} \mathrm{C}$ for three days and dry weight was measured using a micro scale (MC5, Sartorius, Goettingen, Germany) with measuring accuracy of $0.001 \mathrm{mg}$. 


\section{Data analysis}

All statistical tests were performed using Statistica 10 (StatSoft ${ }^{\circledR}$, Tulsa, USA). All data were tested for the normal distribution with the Shapiro-Wilk-test and by visual observation of histograms. Levene's test was carried out to test the equality of variances. Required day-degrees $\left(D^{\circ}\right)$ (dependent variable) for hatching of the three different populations (independent variable) were tested with a Kruskal-WallisANOVA, adjusted with a multiple p-value comparison (two-sided). Hatching rate (dependent variable) of the three different populations (independent variable) was tested with a one-way ANOVA, adjusted with Tukey-Kramer-test to test for differences between the populations. The three populations (independent variable) were tested for differences in their log transformed dry weight $(\mu \mathrm{g})$ respectively their headcapsule width $(\mu \mathrm{m})$ (dependent) as an indicator for development with a one-way ANOVA adjusted with Tukey-Kramer-test. A simple regression was used to quantify the effect of plant height (predictor variable) on WCR development measured as log transformed dry weight $(\mu \mathrm{g})$ and as headcapsule width $(\mu \mathrm{m})$ (dependent variables). The effect of population (independent variable) on recovery rate (\%) of larvae was tested with one-way ANOVA.

Effect of plant height $(\mathrm{cm})$ as the predictor variable on recovery rate $(\%)$ as the dependent variable was quantified with a simple regression. 


\section{Results}

\section{$\underline{\text { Hatch }}$}

Required day-degrees $\left(\mathrm{D}^{\circ}\right)$ differed between the three populations (Kruskal-WallisANOVA, adjusted with a multiple $p$-value comparison (two-sided): $P<0.001, H$ (2, $\mathrm{N}=649)$ = 127.90; Table 2). Highest amount of thermal energy for hatch is needed by the Hungarian field population with $199.9 \mathrm{D}^{\circ}$ (equivalent to Julian day 181) for mean hatch, Serbian population needed $184.7 D^{\circ}$ (JD 178), fewest day-degrees were necessary for mean hatch of the US laboratory population (169.9 ${ }^{\circ} \mathrm{D}$; JD 175). There were no differences (one-way ANOVA $P=0.09, F(2,12)=2.93)$ of hatching rates $(\%)$ between the three populations, average hatching rate was $72.5 \%$.

\section{Development}

Development measured as log larval dry weight $(\mu \mathrm{g})$ (one-way ANOVA: $P=0.03$, $F(2,45)=3.79$, Figure 2 ) or as headcapsule width $(\mu \mathrm{m})$ (one-way ANOVA: $P=0.02$, $F(2,45)=4.25)$ did not differ because the adjustment with Tukey-Kramer test showed no differences between the populations. Development as log larval dry weight $(\mu \mathrm{g})\left(P<0.01\right.$; regression equation: $y=1.02+0.01^{*} x ; R^{2}=0.51$, Figure 2$)$ and as headcapsule width $(\mu \mathrm{m})\left(P<0.01\right.$; regression equation: $y=198.78+1.91^{*} x ; R^{2}=$ $0.39)$ were highly positively correlated with plant height $(\mathrm{cm})$ at the extraction date (Figure 3).

\section{$\underline{\text { Recovery rate }}$}

Larval recovery (\%) was not affected by WCR population (one-way ANOVA: $P=0.88$, $F(2,45)=0.13)$, but was highly positive correlated with plant height $(\mathrm{cm})$ at the extraction date $\left(P<0.01\right.$; regression equation: $\left.y=-9.16+0.49^{*} x ; R^{2}=0.40\right)$. 


\section{Discussion}

In our experiment thermal energy needed for egg hatch differed significantly between the three populations. Hungarian eggs needed about $30 \mathrm{D}^{\circ}$ more for mean hatch, than the US non-diapausing laboratory strain, while the Serbian field population showed intermediate thermal requirements (Table 2; Figure 1). These findings are consistent with a field study using artificial infestations, where larvae of the nondiapausing laboratory strain hatched 6 days earlier than neonates of the wild population (Branson et al. 1981). Hatching rates were not influenced by the origin of the populations. The hatch differences between the populations diminish during larval development (Figure 2). Eventually not all early hatched neonates could establish on the plants or Serbian and US-strain developed slightly slower than the Hungarian did. Differences between the Hungarian and Serbian population were not expected due to the assumption that both populations probable came from the same US source population and the same introduction event. Interestingly, both field strains are known to be resistant against the insecticidal compound aldrin (Ciosi et al. 2008b). Even though the Serbian and the Hungarian strain in our experiment showed significant differences in their thermal requirements for egg hatch. We assumed that the differences between the two field populations indicate a rapid adaptation process of the introduced population.

Some Authors described that insect reared over some generations in the laboratory on artificial diet performed worse than wild types did (Carpenter \& Greany 1998; De Clercq \& Degheele 1992), additionally laboratory rearing can cause changes in behaviour (Spates Jr. \& Hightower 1967) and nutritional preferences (Schoonhoven 1967). Neither growth nor recovery rate did differ between the populations, thus the US non-diapausing population has not lost its viability compared to the tested field populations. The loss of genetic variability which was observed in laboratory colonies of for example Anopheles albimanus Wiedemann (Arias et al. 2005) or the New World sand fly Lutzomyia longipalpis Lutz and Neiva (Mukhopadhyay et al.) was shown for the US WCR non-diapausing population too (Kim et al. 2007). This genetic depletion and divergence had no consequence under moderate conditions like in our experiment for development, but could lead to misleading results when traits like insecticide resistance and behavioural studies are carried out or if responses to extreme conditions are examined. Experiments which deal with plant damage should be carried out carefully, because contradictious results were mentioned in literature. 
While (Branson, Sutter, \& Fisher 1981) showed a less damaging potential of the nondiapausing population, Hibbard et al. 1999 found higher damage levels caused by the non-diapausing population compared to a field population of WCR larvae. We did not test for differences in plant damage in our experiment. Plant growth itself had high impact on development of larvae (Figure 3) and recovery rate in our experiment. On well grown plants we had a higher recovery rate and larvae with a higher dry weight. It can not be clarified whether this was an effect of root quantity or a better food quality or both at high plants. Food quality and quantity both are essential factors for herbivores (Awmack \& Leather 2002). The lack of preferred bigger newly grown nodal roots (Hibbard et al. 2008) or even starvation due to the lack of sufficient root biomass slowed larval development down on small plants compared to bigger plants of the same age.

When specific pest management measures for a region need to be verified, local populations should be used for the experiments. The use of the non-diapausing laboratory population offers benefits like its high availability, uniformity, inability to survive the winter in field (quarantine organism) and its usability over the whole year. For our comparative studies of the WCR traits hatching rate, development and recovery the US non-diapausing laboratory population is a very useful organism when the slight earlier hatch is considered in comparison to field populations. To optimise prediction of WCR hatch in the field further studies for egg development and hatching patterns of different European WCR-populations from different introduction events should be done under regional conditions. 


\section{References}

Arias, L., Bejarano, E.E., Márquez, E., Moncada, J., Vélez, I. \& Uribe, S. (2005) Mitochondrial DNA divergence between wild and laboratory populations of Anopheles albimanus Wiedemann (Diptera: Culicidae). Neotropical Entomology, 34, 499-506.

Awmack, C.S. \& Leather, S.R. (2002) Host plant quality and fecundity in herbivorous insects. Annual Review of Entomology, 47, 817-844.

Branson, T.F. (1976) The selection of a non-diapause strain of Diabrotica virgifera (Coleoptera: Chrysomelidae). Entomologia Experimentalis et Applicata, 19, 148-154.

Branson, T.F., Sutter, G.R. \& Fisher, J.R. (1981) Non-diapause eggs of western corn rootworms in Artificial Field Infestations. Environmental Entomology, 10, 9496.

Carpenter, J.. \& Greany, P.. (1998) Comparative development and performance of artificially reared versus host-reared Diapetimorpha introita(Cresson) (Hymenoptera: Ichneumonidae) wasps. Biological Control, 11, 203-208.

Chiang, H.C. (1973) Bionomics of the northern and western corn rootworms. Annual Review of Entomology, 18, 47-72.

Ciosi, M., Miller, N.J., Kim, K.S., Giordano, R., Estoup, A. \& Guillemaud, T. (2008a) Invasion of Europe by the western corn rootworm, Diabrotica virgifera virgifera: multiple transatlantic introductions with various reductions of genetic diversity. Molecular Ecology, 17, 3614-3627.

Ciosi, M., Toepfer, S., Li, H., Haye, T., Kuhlmann, U., Wang, H., Siegfried, B. \& Guillemaud, T. (2008b) European populations of Diabrotica virgifera virgifera are resistant to aldrin, but not to methyl-parathion. Journal of Applied Entomology, 133, 307-314.

De Clercq, P. \& Degheele, D. (1992) A meat-based diet for rearing the predatory stinkbugs Podisus maculiventris and Podisus sagitta [Het.: Pentatomidae]. Entomophaga, 37, 149-157.

Davis, P.M., Brenes, N. \& Allee, L.L. (1996) Temperature dependent models to predict regional differences in corn rootworm (Coleoptera: Chrysomelidae) phenology. Environmental Entomology, 25, 767-775.

EPPO. (2011) Diabrotica virgifera, http://www.eppo.org/QUARANTINE/Diabrotica_virgifera/diabrotica_virgifera.ht $\mathrm{m}$

Gray, M.E., Sappington, T.W., Miller, N.J., Moeser, J. \& Bohn, M.O. (2009) Adaptation and invasiveness of western corn rootworm: intensifying research on a worsening pest. Annual Review of Entomology, 54, 303-321. 
Hammack, L., Ellsbury, M.M., Roehrdanz, R.L. \& Pikul, J.L. (2003) Larval sampling and instar determination in field populations of northern and western corn rootworm (Coleoptera: Chrysomelidae). Journal of Economic Entomology, 96, 1153-1159.

Hibbard, B.E., Barry, B.D., Darrah, L.L., Jackson, J.J., Chandler, L.D., French, L.K. \& Mihm, J.A. (1999) Controlled field infestations with western corn rootworm (Coleoptera: Chrysomelidae) eggs in Missouri: effects of egg strains, infestation dates, and infestation levels on corn root damage. Journal of the Kansas Entomological Society, 72, 214-221.

Hibbard, B.E., Schweikert, Y.M., Higdon, M.L. \& Ellersieck, M.R. (2008) Maize phenology affects establishment, damage, and development of the western corn rootworm (Coleoptera: Chrysomelidae). Environmental Entomology, 37, 1558-1564.

James R. Fisher. (1989) Hatch of Diabrotica virgifera virgifera (Coleoptera: Chrysomelidae) eggs exposed to two different overwintering and hatch regimes. Journal of the Kansas Entomological Society, 62, 607-610.

Kempson, D., Lloyd, M. \& Ghelardi, R. (1963) A new extractor for woodland litter. Pedobiologia, 3, 1-21.

Kim, K.S. \& Sappington, T.W. (2005) Genetic structuring of western corn rootworm (Coleoptera: Chrysomelidae) populations in the United States based on microsatellite loci analysis. Environmental Entomology, 34, 494-503.

Kim, K.S., French, B.W., Sumerford, D.V. \& Sappington, T.W. (2007) Genetic diversity in laboratory colonies of western corn rootworm (Coleoptera: Chrysomelidae), including a nondiapause colony. Environmental Entomology, 36, 637-645.

Levine, E., Oloumi-Sadeghi, H. \& Ellis, C.R. (1992) Thermal requirements, hatching patterns, and prolonged diapause in western corn rootworm (Coleoptera: Chrysomelidae) eggs. Journal of Economic Entomology, 85, 2425-2432.

Levine, E., Spencer, J.L., Isard, S.A., Onstad, D.W. \& Gray, M.E. (2002) Adaptation of the western corn rootworm to crop rotation: evolution of a new strain in response to a management practice. American Entomologist, 48, 94-117.

Meinke, L.J., Siegfried, B.D., Wright, R.J. \& Chandler, L.D. (1998) Adult susceptibility of Nebraska western corn rootworm (Coleoptera: Chrysomelidae) populations to selected insecticides. Journal of Economic Entomology, 91, 594-600.

Melhus, I.E., Painter, R.H. \& Smith, F.O. (1954) A search for resistance to the injury caused by species of Diabrotica in the corns of Guatemala. lowa State Coll. J. Sci., 29, 75-94.

Mukhopadhyay, J., Rangel, E.F., Ghosh, K. \& Munstermann, L.E. Patterns of genetic variability in colonized strains of Lutzomyia longipalpis (diptera: Psychodidae) and its consequences. The American journal of tropical medicine and hygiene, $57,216-221$. 
Ruppel, R.F., Russell, H.L. \& Jennings, S.J. (1978) Indices for projecting emergence of corn rootworm adults in Michigan. Journal of Economic Entomology, 71, 947-949.

Sappington, T.W., Siegfried, B.D. \& Guillemaud, T. (2006) Coordinated Diabrotica genetics research: accelerating progress on an urgent insect pest problem. American Entomologist, 52, 90-97.

Schaafsma, A.W., Whitfield, G.H. \& Ellis, C.R. (1991) A temperature-dependent model of egg development of the western corn rootworm, Diabrotica virgifera virgifera LeConte (Coleoptera: Chrysomelidae). The Canadian Entomologist, 123, 1183-1197.

Schoonhoven, L.M. (1967) Loss of hostplant specificity by Manduca sexta after rearing on an artificial diet. Entomologia Experimentalis et Applicata, 10, 270272.

Spates Jr., G.E. \& Hightower, B.G. (1967) Sexual aggressiveness of male screwworm flies affected by laboratory rearing. Journal of Economic Entomology, $60,752-755$.

Szalai, M., Papp Komáromi, J., Bažok, R., Igrc Barčić, J., Kiss, J. \& Toepfer, S. (2010) Generational growth rate estimates of Diabrotica virgifera virgifera populations (Coleoptera: Chrysomelidae). Journal of Pest Science, 84, 133142.

Wesseler, J. \& Fall, E.H. (2010) Potential damage costs of Diabrotica virgifera virgifera infestation in Europe - the "no control" Scenario. , 134, 385-394.

Wilde, G.E. (1971) Temperature effect on development of western corn rootworm eggs. Journal of the Kansas Entomological Society, 44, 185-187.

Wilde, G., Chiang, H.C., Hibbs, E.T. \& Lawson, D.E. (1972) Variation in egg hatch among western and northern corn rootworms from six midwestern States. Journal of the Kansas Entomological Society, 45, 259-263.

Wright, R.J., Scharf, M.E., Meinke, L.J., Zhou, X., Siegfried, western corn rootworm (Coleoptera: Chrysomelidae) population to soil insecticides: laboratory bioassays, assays of detoxification enzymes, and field performance. Journal of Economic Entomology, 93, 7-13. 


\section{Annex}

\section{$\underline{\text { Tables }}$}

Table 1: weekly adjusted experimental mean temperatures calculated from historical (19712000) data from the DWD (Deutscher Wetterdienst) in Lingen. Julian Day 121 is experimental day 1 and corresponds to the 1 . May in the field

\begin{tabular}{cc} 
Julian Day & $\mathrm{T}$ (mean) $\left({ }^{\circ} \mathrm{C}\right)$ \\
\hline $121-127$ & 11.4 \\
$128-134$ & 12.8 \\
$135-141$ & 13.9 \\
$142-148$ & 13.9 \\
$149-155$ & 14.9 \\
$156-162$ & 15.4 \\
$163-169$ & 15.5 \\
$170-176$ & 15.5 \\
$177-183$ & 16.5 \\
$184-190$ & 17.9 \\
$191-197$ & 17.7 \\
$198-204$ & 17.2 \\
$205-211$ & 17.9 \\
$212-218$ & 18.6 \\
\hline
\end{tabular}

Table 2: Day-degrees $\left(D^{\circ}\right)$ for mean hatch, first larval hatch $\left(\min D^{\circ}\right)$, hatch of last larva (max $D^{\circ}$ ) and standard deviation (SD) in the hatch tests ( $N_{\text {Hungary }}=271 ; N_{\text {Serbia }}=281 ; N_{U S}=97$ ).

\begin{tabular}{ccccc} 
Population & $\operatorname{mean} \mathrm{D}^{\circ}$ & $\min \mathrm{D}^{\circ}$ & $\max \mathrm{D}^{\circ}$ & $\mathrm{SD}$ \\
\hline US & 169.6 & 136.6 & 297.4 & 25.9 \\
Serbia & 184.7 & 145.6 & 297.4 & 21.9 \\
Hungary & 199.9 & 154.6 & 304.1 & 25.8 \\
\hline
\end{tabular}


$\underline{\text { Figures }}$

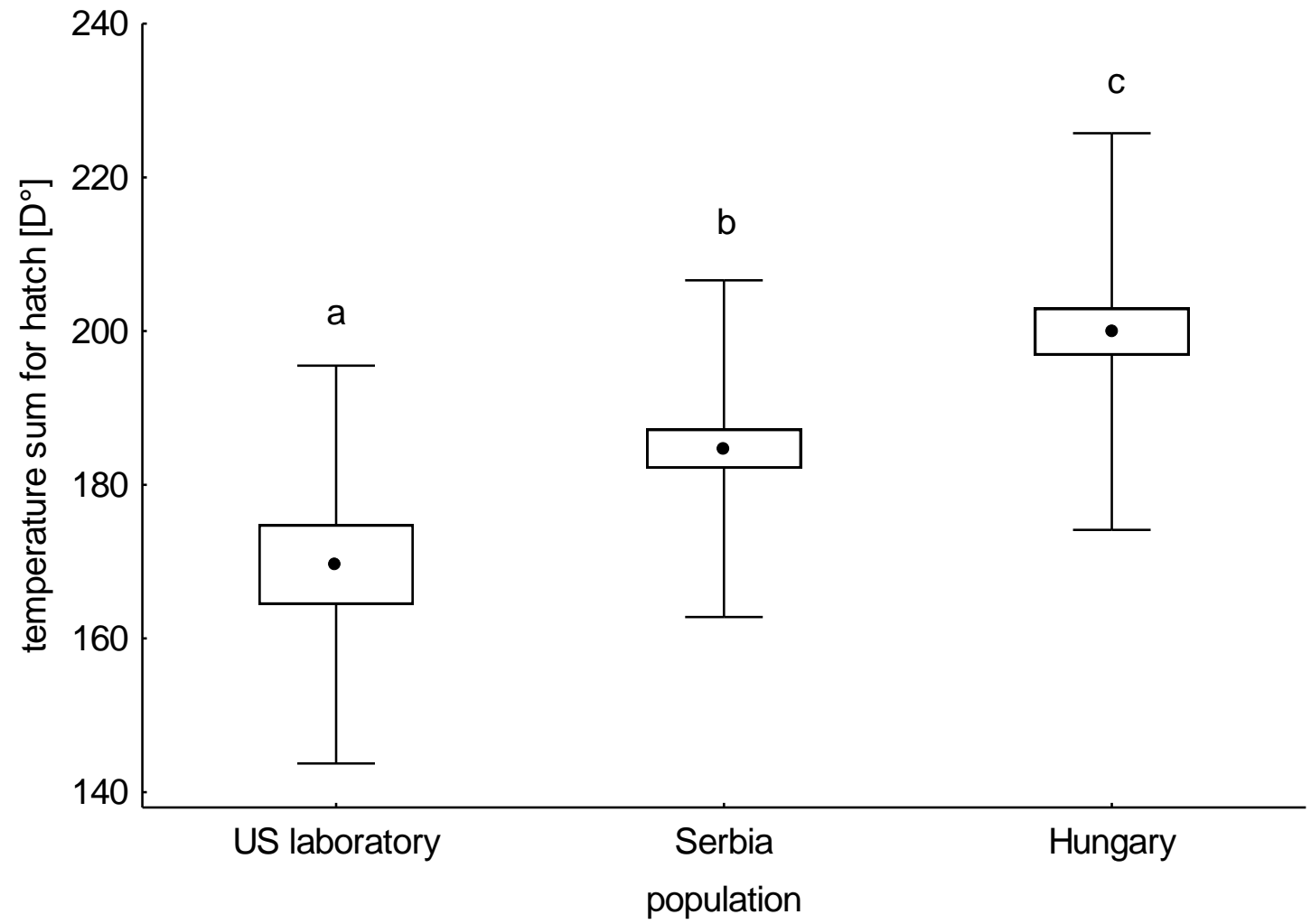

Figure 1: Temperature sum $\left(D^{\circ}\right)$ for a base temperature of $11^{\circ} \mathrm{C}$ required for hatch of the three different WCR populations (Kruskal-Wallis-ANOVA; dot = mean, box = mean $\pm 0.95 \mathrm{Cl}$, whisker = mean $\pm \mathrm{SD}$; letters indicate significant statistical differences; replicates = plants $\mathbf{N}_{\text {Hungary }}$ $=271 ; N_{\text {Serbia }}=281 ; N_{U S}=97$ ). 


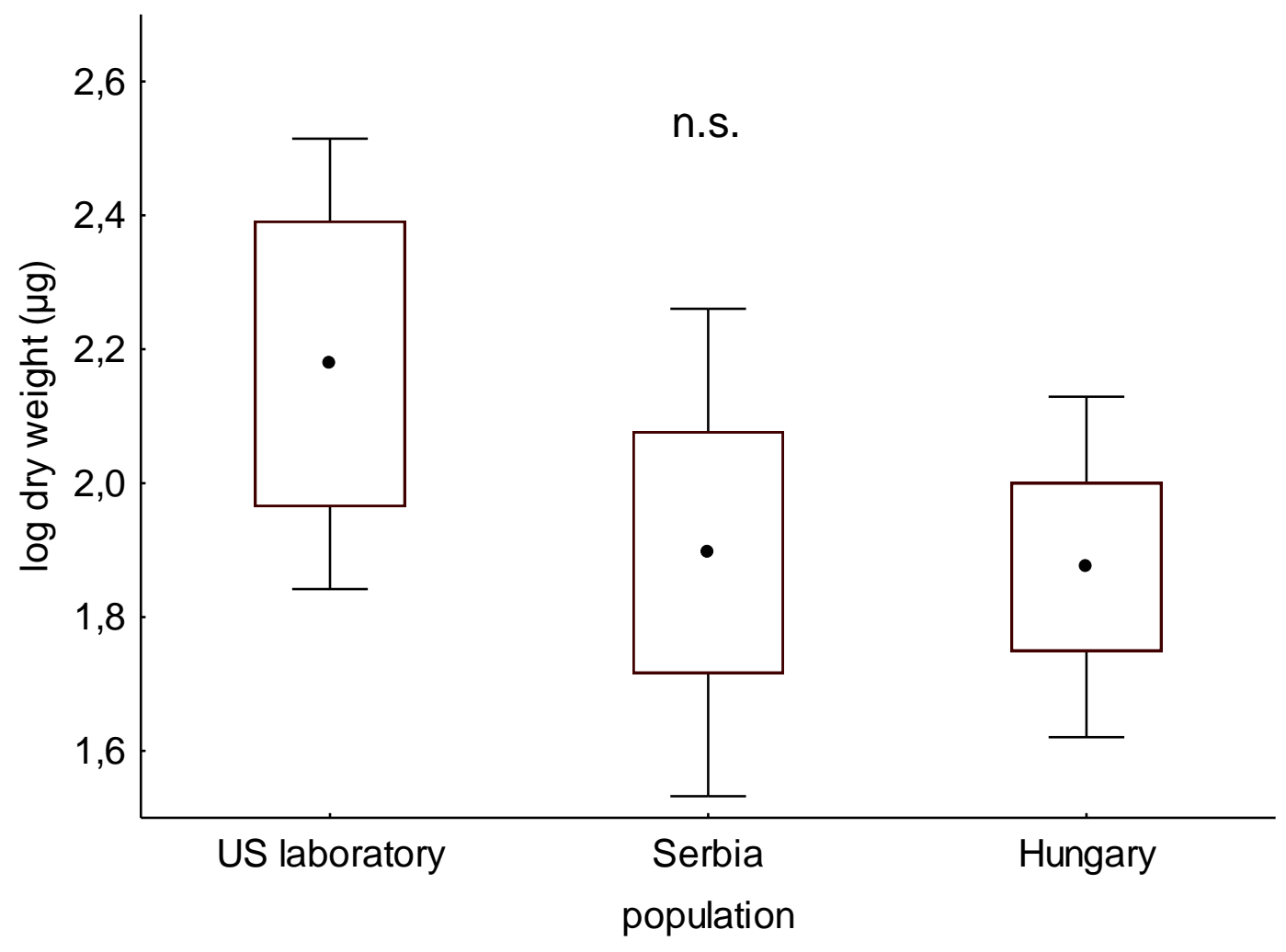

Figure 2: Compared larval development as log larval dry weight $(\mu \mathrm{g})$ of the three different WCR populations (Kruskal-Wallis-ANOVA; dot = mean, box $=$ mean $\pm 0.95 \mathrm{Cl}$, whisker $=$ mean $\pm \mathrm{SD}$; n. $s$. = no significant statistical differences; replicates = plants: $N_{\text {Hungary }}=18 ; N_{\text {Serbia }}=18 ; N_{U S}=12$ ). 


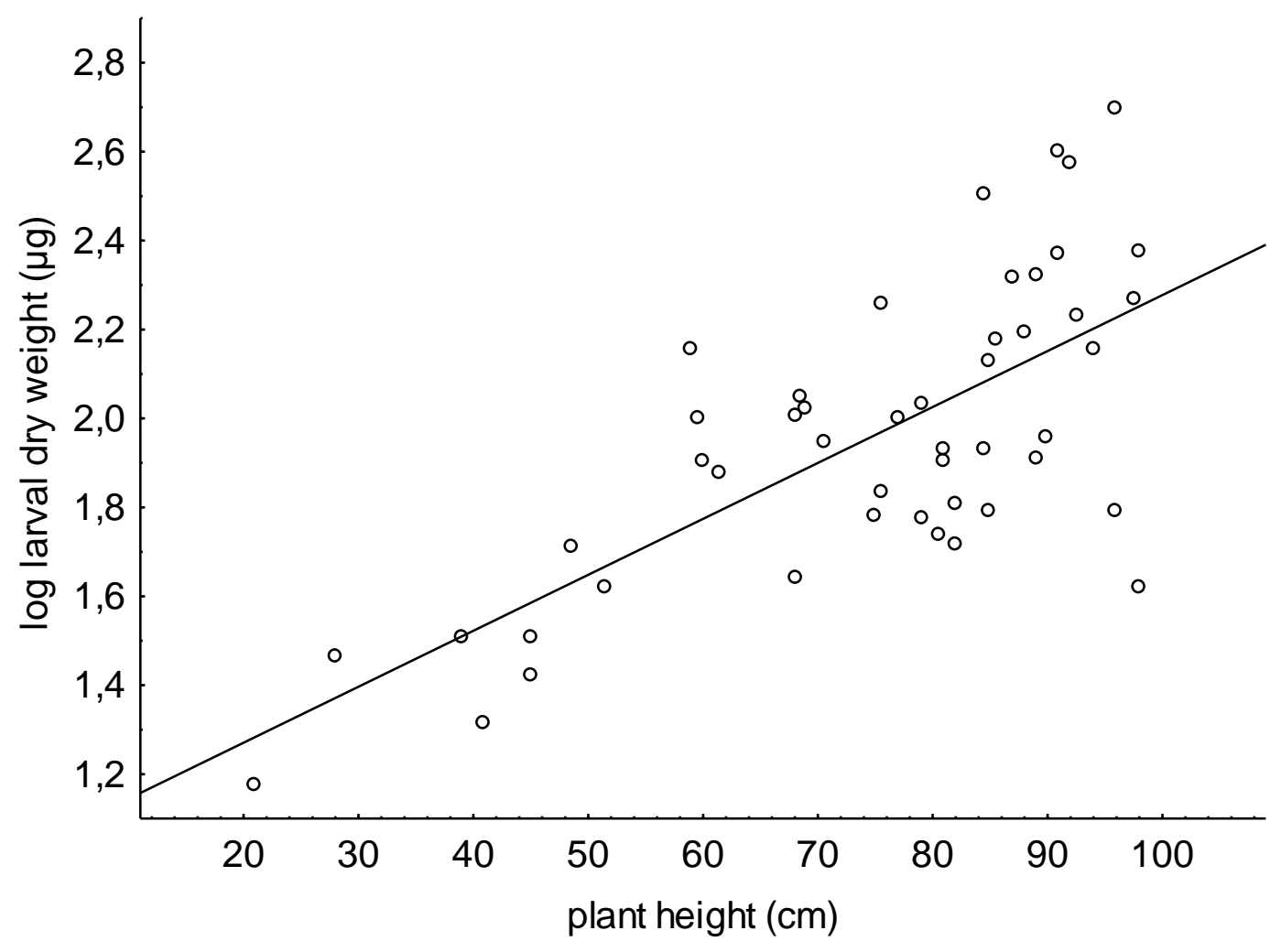

Figure 3: Correlation between log larval dry weight $(\mu \mathrm{g})$ and plant height $(\mathrm{cm})$ at extraction date. 


\section{General discussion}

The western corn rootworm is well established in Europe and eradication of this maize pest unfeasible (Hummel \& Deuker 2009). Extensive eradication and containment measures retarded WCR dispersion in Europe, but did not stop it. Even crop rotation is not sufficient to exclude WCR development, because of a low proportion of larvae which are able to develop on alternative host plants (Moeser \& Vidal 2004; Chege, Clark, \& Hibbard 2005) and a small proportion of females which lay eggs in non-maize fields. There is continuing extension of maize growing area for energy generation in Europe (Sims et al. 2006). Hence, there is a basic necessity of key data to establish regional integrated pest management strategies against WCR. Even though WCR larvae are soil insects, all the noted experimental temperatures were air temperatures. Elliott et al. stated that air temperatures are as well suitable to predict WCR development as soil temperature are (Elliott, Jackson, \& Gustin 1990).

We studied the influence of an enhanced temperature on the synchrony of maize and pest in Northern Germany. Our experiment had the same limitation Musolin et al. mentioned in their work about the southern green stinkbug Nezara viridula (Musolin, Tougou, \& Fujisaki 2010), we used fixed increase in temperature, while climate change predictions differ between the seasons with especially a warmer winter in northern hemisphere (Houghton et al. 2001). We looked on a scenario with increased spring and summer temperatures and a further begin of activity. Climate change will not only become manifest as global warming, but will also impact extreme events, carbon dioxide and precipitation (Harrington, Fleming, \& Woiwod 2001). Jentsch et al. noted that climate change research has to deal with "events not trends." (Jentsch, Kreyling, \& Beierkuhnlein 2007), since extreme events have a very high influence on ecological processes. Nevertheless we found an influence of a moderate later sowing on larval development under a warmed temperature regime, assumedly due to a higher mortality of early hatched larvae on little developed plants. The possibility of the disruption of host-pest synchrony should be considered as a management strategy in infested second-year maize under a changing climate with its predicted longer growing seasons (Cannon 1998). Higher infestations levels will potentially lead to a higher degree of efficiency of this measure, because a higher mortality by intraspecific competition on small root systems (Bergman \& Turpin 1984). Because of the contradicting findings of former studies (Branson \& Sutter 1986; Hibbard et al. 1999, 
2008), plant damage and resulting yield losses should be examined thoroughly. Precipitation and irrigation additionally influence WCR development and the regrowth potential of the plant.

We examined in the first experiment the effect of diurnal temperature alteration of two magnitudes $\left(4^{\circ} \mathrm{C}\right.$ and $6^{\circ} \mathrm{C}$ difference) on WCR development compared with the adequate constant mean temperature. In the second experiment we reared the eggs under 6 different experimental temperatures: high $\left(20^{\circ} \mathrm{C}\right)$, mediate $\left(17^{\circ} \mathrm{C}\right)$ and low $\left(14^{\circ} \mathrm{C}\right)$ constant temperatures and the diurnal $(12 \mathrm{~h} / 12 \mathrm{~h})$ by $8^{\circ} \mathrm{C}$ varying counterparts of the same mean $\left(16 / 24^{\circ} \mathrm{C}, 13 / 21^{\circ} \mathrm{C}, 10 / 18^{\circ} \mathrm{C}\right)$. We found a high influence of alternating temperatures on hatching as the intrinsic factor for the timing of management measures. Western corn rootworm egg and larval development was significant enhanced at varying temperatures compared with constant temperatures. This phenomenon is known as Kaufmann effect or rate summation and the reason for this accelerated development is the logistic correlation of development rate and temperature for insects, the temperature sum deviate from predicted values if the temperature is below or above the area of linear dependence (Kaufmann 1932). This effect should be taken into account for the prediction of larval hatch. Even though it is clear that the differences of the hatching patterns were pure temperature effects the larval development could be influenced by behavioural changes like a circadian feeding behaviour (Miyashita 1971; Behrens et al. 1983) of WCR-larvae as adaptation to naturally varying temperatures, gas proportions or humidity conditions. Additionally plant growth and chemical composition of the host plant are highly temperature affected which could lead to a deviating host suitability (Went 1953; Leather 2010). In all of our experiments there was a strong positive correlation between plant height and larval performance respectively plant height and larval recovery. To exclude the effect of plant growth and observe direct temperature effects on larval development, larvae should be reared on an artificial diet in a further experiment.

We compared two different European western corn rootworm field populations from Serbia and Hungary with the US non-diapausing laboratory population. We found a slight higher thermal requirement for hatching of the Hungarian and the Serbian population compared to the laboratory population. We assumed that the differences 
between the two field populations indicate an adaptation process of the introduced population. US non-diapausing laboratory population showed not the loss of viability which is reported from other laboratory reared insect cultures (Carpenter \& Greany 1998; De Clercq \& Degheele 1992), even though a genetic depletion is evidenced in this population (Kim \& Sappington 2005). This genetic depletion and divergence had no consequence under moderate conditions like in our experiment for development, but could lead to misleading results when studies were carried out addressing the responses to extreme conditions, the behaviour or resistance traits. It would be interesting to study differences between European populations from different introduction events. For the implementation of regional pest management strategies local populations should be used. The benefits of the non-diapausing laboratory population are very high and for our comparing studies of the WCR traits hatching rate, development and recovery the US non-diapausing laboratory population was a very useful organism. The earlier hatch has to be considered in comparison to field populations. 


\section{References of general introduction and general discussion}

Allen, M.R., Stott, P.A., Mitchell, J.F.B., Schnur, R. \& Delworth, T.L. (2000) Quantifying the uncertainty in forecasts of anthropogenic climate change. Nature, 407, 617620.

Awmack, C.S. \& Leather, S.R. (2002) Host plant quality and fecundity in herbivorous insects. Annual Review of Entomology, 47, 817-844.

Baufeld, P., Enzian, S. \& Motte, G. (1996) Establishment potential of Diabrotica virgifera in Germany. EPPO Bulletin, 26, 511-518.

Beck, S.D. (1983) Thermal and thermoperiodic effects on larval development and diapause in the European corn borer, Ostrinia nubilalis. Journal of Insect Physiology, 29, 107-112.

Behrens, W., Hoffmann, K.-H., Kempa, S., Gäßler, S. \& Merkel-Wallner, G. (1983) Effects of diurnal thermoperiods and quickly oscillating temperatures on the development and reproduction of crickets, Gryllus bimaculatus. Oecologia, 59, 279-287.

Bergant, K. \& Trdan, S. (2006) How reliable are thermal constants for insect development when estimated from laboratory experiments? Entomologia Experimentalis et Applicata, 120, 251-256.

Bergman, M.K. \& Turpin, F.T. (1984) Impact of corn planting date on the population dynamics of corn rootworms (Coleoptera: Chrysomelidae). Environmental Entomology, 13, 898-901.

Branson, T.F. \& Sutter, G.R. (1986) Influence of application date on damage resulting from controlled infestations with eggs of Diabrotica virgifera virgifera (Coleoptera: Chrysomelidae). Journal of Economic Entomology, 79, 838-839.

Buse, A. \& Good, J. (1996) Synchronization of larval emergence in winter moth (Operophtera brumata L.) and budburst in pedunculate oak (Quercus robur L.) under simulated climate change. Ecological Entomology, 21, 335-343.

Cannon, R.J.C. (1998) The implications of predicted climate change for insect pests in the UK, with emphasis on non-indigenous species. Global Change Biology, 4, 785-796.

Carpenter, J. \& Greany, P. (1998) Comparative development and performance of artificially reared versus host-reared Diapetimorpha introita(Cresson) (Hymenoptera: Ichneumonidae) wasps. Biological Control, 11, 203-208.

Chege, P.G., Clark, T.L. \& Hibbard, B.E. (2005) Alternate host phenology affects survivorship, growth, and development of western corn rootworm (Coleoptera: Chrysomelidae) larvae. Environmental Entomology, 34, 1441-1447.

Chiang, H.C. (1973) Bionomics of the northern and western corn rootworms. Annual Review of Entomology, 18, 47-72. 
Ciosi, M., Miller, N.J., Kim, K.S., Giordano, R., Estoup, A. \& Guillemaud, T. (2008) Invasion of Europe by the western corn rootworm, Diabrotica virgifera virgifera: multiple transatlantic introductions with various reductions of genetic diversity. Molecular Ecology, 17, 3614-3627.

De Clercq, P. \& Degheele, D. (1992) A meat-based diet for rearing the predatory stinkbugsPodisus maculiventris andPodisus sagitta [Het.: Pentatomidae]. Entomophaga, 37, 149-157.

Damos, P. \& Savopoulou-Soultani, M. (2012) Temperature-driven models for insect development and vital thermal requirements. Psyche: A Journal of Entomology, 2012, 1-13.

Davis, P.M., Brenes, N. \& Allee, L.L. (1996) Temperature dependent models to predict regional differences in corn rootworm (Coleoptera: Chrysomelidae) phenology. Environmental Entomology, 25, 767-775.

Dewar, R.C. \& Watt, A.D. (1992) Predicted changes in the synchrony of larval emergence and budburst under climatic warming. Oecologia, 89, 557-559.

Edwards, C.R. \& Kiss, J. (2012) Western Corn Rootworm at Purdue University, http://extension.entm.purdue.edu/wcr/

Elliott, N.C., Jackson, J.J. \& Gustin, R.D. (1990) Predicting western corn rootworm beetle (Coleoptera: Chrysomelidae) emergence from the soil using soil or air temperature. The Canadian Entomologist, 122, 1079-1091.

EPPO. (2011) Diabrotica virgifera, http://www.eppo.org/QUARANTINE/Diabrotica_virgifera/diabrotica_virgifera.htm

Fisher, J.R. (1989) Hatch of Diabrotica virgifera virgifera (Coleoptera: Chrysomelidae) eggs exposed to two different overwintering and hatch regimes. Journal of the Kansas Entomological Society, 62, 607-610.

Gassmann, A.J., Petzold-Maxwell, J.L., Keweshan, R.S. \& Dunbar, M.W. (2011) Fieldevolved resistance to Bt maize by western corn rootworm. PLoS ONE, 6, e22629.

Gray, M.E. (2010) Relevance of traditional integrated pest management (IPM) strategies for commercial corn producers in a transgenic agroecosystem: a bygone era? J. Agric. Food Chem., 59, 5852-5858.

Gray, M.E., Sappington, T.W., Miller, N.J., Moeser, J. \& Bohn, M.O. (2009) Adaptation and invasiveness of western corn rootworm: intensifying research on a worsening pest. Annual Review of Entomology, 54, 303-321.

Gregory, P.J., Johnson, S.N., Newton, A.C. \& Ingram, J.S.I. (2009) Integrating pests and pathogens into the climate change/food security debate. Journal of Experimental Botany, 60, 2827-2838.

Harrington, R., Fleming, R.A. \& Woiwod, I.P. (2001) Climate change impacts on insect management and conservation in temperate regions: can they be predicted? Agricultural and Forest Entomology, 3, 233-240. 
Hibbard, B.E., Barry, B.D., Darrah, L.L., Jackson, J.J., Chandler, L.D., French, L.K. \& Mihm, J.A. (1999) Controlled field infestations with western corn rootworm (Coleoptera: Chrysomelidae) eggs in Missouri: effects of egg strains, infestation dates, and infestation levels on corn root damage. Journal of the Kansas Entomological Society, 72, 214-221.

Hibbard, B.E., Schweikert, Y.M., Higdon, M.L. \& Ellersieck, M.R. (2008) Maize phenology affects establishment, damage, and development of the western corn rootworm (Coleoptera: Chrysomelidae). Environmental Entomology, 37, 1558-1564.

Houghton, J.T., Ding, Y., Griggs, D.J., Noguer, M., van der Linden, P.J., Dai, X., Maskell, K. \& Johnson, C.A. (2001) Climate Change 2001: The Scientific Basis. Cambridge University Press Cambridge.

Howe, R.W. (1967) Temperature effects on embryonic development in insects. Annual Review of Entomology, 12, 15-42.

Hummel, H.E. \& Deuker, A. (2009) Western corn rootworm Diabrotica v. virgifera in Europe: status, and options for future management. Communications in Agricultural and Applied Biological Sciences, 74, 271-278.

IPCC, I.P. on C. \& I, I.P. on C.C.W.G. (2007) Climate change 2007: The physical science basis: contribution of working group I to the fourth assessment report of the intergovernmental panel on climate change. Cambridge University Press.

Jentsch, A., Kreyling, J. \& Beierkuhnlein, C. (2007) A new generation of climatechange experiments: events, not trends. Frontiers in Ecology and the Environment, 5, 365-374.

Johnson, S.N., Barton, A.T., Clark, K.E., Gregory, P.J., McMenemy, L.S. \& Hancock, R.D. (2011) Elevated atmospheric carbon dioxide impairs the performance of root-feeding vine weevils by modifying root growth and secondary metabolites. Global Change Biology, 17, 688-695.

Kahler, A., Olness, A., Sutter, G., Dybing, C. \& Devine, O. (1985) Root damage by western corn rootworm and nutrient content in maize. Agron. J, 77, 769-774.

Kaufmann, O. (1932) Einige Bemerkungen über den Einfluss von Temperaturschwankungen auf die Entwicklungsdauer und Streuung bei Insekten und seine graphische Darstellung durch Kettenlinie und Hyperbel. Zeitschrift für Morphologie und Ökologie der Tiere, 25, 353-361.

Kim, K.S. \& Sappington, T.W. (2005) Genetic structuring of western corn rootworm (Coleoptera: Chrysomelidae) populations in the United States based on microsatellite loci analysis. Environmental Entomology, 34, 494-503.

Leather, S.R. (2010) Precise knowledge of plant growth stages enhances applied and pure research. Annals of Applied Biology, 157, 159-161.

Levine, E., Oloumi-Sadeghi, H. \& Ellis, C.R. (1992) Thermal requirements, hatching patterns, and prolonged diapause in western corn rootworm (Coleoptera: Chrysomelidae) eggs. Journal of Economic Entomology, 85, 2425-2432. 
Levine, E., Spencer, J.L., Isard, S.A., Onstad, D.W. \& Gray, M.E. (2002) Adaptation of the western corn rootworm to crop rotation: evolution of a new strain in response to a management practice. American Entomologist, 48, 94-117.

Liu, S.-S., Zhang, G.-M. \& Zhu, J. (1995) Influence of temperature variations on rate of development in insects: analysis of case studies from entomological literature. Annals of the Entomological Society of America, 88, 107-119.

Meinke, L.J., Siegfried, B.D., Wright, R.J. \& Chandler, L.D. (1998) Adult susceptibility of Nebraska western corn rootworm (Coleoptera: Chrysomelidae) populations to selected insecticides. Journal of Economic Entomology, 91, 594-600.

Melhus, I.E., Painter, R.H. \& Smith, F.O. (1954) A search for resistance to the injury caused by species of Diabrotica in the corns of Guatemala. lowa State Coll. J. Sci., 29, 75-94.

Miyashita, K. (1971) Effects of constant and alternating temperatures on the development of Spodoptera litura F.: Lepidoptera: Noctuidae. Applied entomology and zoology, 6, 105-111.

Moeser, J. \& Vidal, S. (2004) Do alternative host plants enhance the invasion of the maize pest Diabrotica virgifera virgifera (Coleoptera: Chrysomelidae, Galerucinae) in Europe? Environmental Entomology, 33, 1169-1177.

Mooney, H.A. \& Hobbs, R.J. (2000) Invasive species in a changing world. Island Press.

Musolin, D.L., Tougou, D. \& Fujisaki, K. (2010) Too hot to handle? Phenological and life-history responses to simulated climate change of the southern green stink bug Nezara viridula (Heteroptera: Pentatomidae). Global Change Biology, 16, 73-87.

National Invasive Species Council. (2006) Invasive species definition clarification and guidance white paper. Other Publications in Wildlife Management.

Oleson, J.D., Park, Y.-L., Nowatzki, T.M. \& Tollefson, J.J. (2005) Node-injury scale to evaluate root injury by corn rootworms (Coleoptera: Chrysomelidae). Journal of Economic Entomology, 98, 1-8.

Parmesan, C. \& Yohe, G. (2003) A globally coherent fingerprint of climate change impacts across natural systems. Nature, 421, 37-42.

Pimentel, D., Lach, L., Zuniga, R. \& Morrison, D. (2008) Economic costs of nonindigenous species in the United States. BioScience, 50, 53-65.

Pimentel, D., Zuniga, R. \& Morrison, D. (2005) Update on the environmental and economic costs associated with alien-invasive species in the United States. Ecological Economics, 52, 273-288.

Porter, J.H., Parry, M.L. \& Carter, T.R. (1991) The potential effects of climatic change on agricultural insect pests. Agricultural and Forest Meteorology, 57, 221-240. 
Rannow, S., Loibl, W., Greiving, S., Gruehn, D. \& Meyer, B.C. (2010) Potential impacts of climate change in Germany-Identifying regional priorities for adaptation activities in spatial planning. Landscape and Urban Planning, 98, 160-171.

Riedell, W.E. (1990) Rootworm and mechanical damage effects on root morphology and water relations in maize. Crop Science, 30, 628.

Ruppel, R.F., Russell, H.L. \& Jennings, S.J. (1978) Indices for projecting emergence of corn rootworm adults in Michigan. Journal of Economic Entomology, 71, 947949.

Sappington, T.W., Siegfried, B.D. \& Guillemaud, T. (2006) Coordinated Diabrotica genetics research: accelerating progress on an urgent insect pest problem. American Entomologist, 52, 90-97.

Schaafsma, A.W., Baufeld, P. \& Ellis, C.R. (1999) Influence of cropping practices on corn rootworm in Canada as a basis for assessment of the potential impact of Diabrotica virgifera in Germany. EPPO Bulletin, 29, 145-154.

Sims, R.E.H., Hastings, A., Schlamadinger, B., Taylor, G. \& Smith, P. (2006) Energy crops: current status and future prospects. Global Change Biology, 12, 20542076.

Spencer, J.L., Hibbard, B.E., Moeser, J. \& Onstad, D.W. (2009) Behaviour and ecology of the western corn rootworm (Diabrotica virgifera virgifera LeConte).

Agricultural and Forest Entomology, 11, 9-27.

Spike, B.P. \& Tollefson, J.J. (1989) Relationship of plant phenology to corn yield loss resulting from western corn rootworm (Coleoptera: Chrysomelidae) larval injury.,Nitrogen Deficiency., and High Plant Density. Journal of Economic Entomology, 82, 226-231.

Stainforth, D.A., Aina, T., Christensen, C., Collins, M., Faull, N., Frame, D.J., Kettleborough, J.A., Knight, S., Martin, A., Murphy, J.M., Piani, C., Sexton, D., Smith, L.A., Spicer, R.A., Thorpe, A.J. \& Allen, M.R. (2005) Uncertainty in predictions of the climate response to rising levels of greenhouse gases. Nature, 433, 403-406.

Stange, E.E. \& Ayres, M.P. (2010) Climate change impacts: insects. Encyclopedia of Life Sciences (ed John Wiley \& Sons, Ltd), p. John Wiley \& Sons, Ltd, Chichester, UK.

Szalai, M., Papp Komáromi, J., Bažok, R., Igrc Barčić, J., Kiss, J. \& Toepfer, S. (2010) Generational growth rate estimates of Diabrotica virgifera virgifera populations (Coleoptera: Chrysomelidae). Journal of Pest Science, 84, 133-142.

Thomas, C.D., Cameron, A., Green, R.E., Bakkenes, M., Beaumont, L.J., Collingham, Y.C., Erasmus, B.F.N., Siqueira, M.F. de, Grainger, A., Hannah, L., Hughes, L., Huntley, B., Jaarsveld, A.S. van, Midgley, G.F., Miles, L., Ortega-Huerta, M.A., Peterson, A.T., Phillips, O.L. \& Williams, S.E. (2004) Extinction risk from climate change. Nature, 427, 145-148. 
Tylianakis, J.M., Didham, R.K., Bascompte, J. \& Wardle, D.A. (2008) Global change and species interactions in terrestrial ecosystems. Ecology Letters, 11, 13511363.

Vidal, S., Kuhlmann, U. \& Edwards, C.R. (2005) Western Corn Rootworm: ecology and management. CABI.

Walther, G.-R., Post, E., Convey, P., Menzel, A., Parmesan, C., Beebee, T.J.C., Fromentin, J.-M., Hoegh-Guldberg, O. \& Bairlein, F. (2002) Ecological responses to recent climate change. Nature, 416, 389-395.

Went, F.W. (1953) The effect of temperature on plant growth. Annual Review of Plant Physiology, 4, 347-362.

Wesseler, J. \& Fall, E.H. (2010) Potential damage costs of Diabrotica virgifera virgifera infestation in Europe - the 'no control' Scenario. , 134, 385-394.

Wilde, G.E. (1971) Temperature effect on development of western corn rootworm eggs. Journal of the Kansas Entomological Society, 44, 185-187.

Wilde, G., Chiang, H.C., Hibbs, E.T. \& Lawson, D.E. (1972) Variation in egg hatch among western and northern corn rootworms from six midwestern states. Journal of the Kansas Entomological Society, 45, 259-263.

Williamson, M.H. \& Fitter, A. (1996) The characters of successful invaders. Biological Conservation, 78, 163-170.

Wright, R.J., Scharf, M.E., Meinke, L.J., Zhou, X., Siegfried, B.D. \& Chandler, L.D. (2000) Larval susceptibility of an insecticide-resistant western corn rootworm (Coleoptera: Chrysomelidae) population to soil insecticides: laboratory bioassays, assays of detoxification enzymes, and field performance. Journal of Economic Entomology, 93, 7-13.

Ziska, L.H., Blumenthal, D.M., Runion, G.B., Hunt, E.R. \& Diaz-Soltero, H. (2010) Invasive species and climate change: an agronomic perspective. Climatic Change, 105, 13-42. 


\section{Acknowledgements / Danksagung:}

Prof. Dr. Stefan Vidal möchte ich für mein Thema danken, für das Vertrauen ("Hast du sicher schon erledigt?") und den Freiraum für eine selbstständige Arbeit.

Prof. Dr. Teja Tscharntke möchte ich für die bereitwillige Übernahme des CoReferats danken und Prof. Dr. Johannes Isselstein, der die Aufgabe als Drittprüfer übernommen hat.

Ich danke dem Niedersächsischen Ministerium für Wissenschaft und Kultur für die Finanzierung dieses interessanten Projektes sowie dem KLIFF-Verbundprojekt für eine schöne Zusammenarbeit. Besonders danke ich Dr. Peter Juroszek, der uns immer wieder alle unter einen Hut gebracht hat.

Ich danke herzlich meinen lieben Kollegen für ihre sowohl unbezahlbare als auch unbezahlte Hilfe und für viel Spaß und Unterstützung, ohne die meine Arbeit nicht möglich gewesen wäre.

Besonders geht mein Dank an Lana Dobrindt und Antje Reinhardt, meine unverzichtbaren Stützen, Mario Schumann, Bianca Tappe und Benedikt Kurtz als Mitglieder im „Team-Diabrotica“, Dr. Bernd Ulber für anregende Gespräche, Helge Stahlmann und Alexander Döring für kreative Unterstützung und Materialbeschaffung. Unersetzlich war Frank Gremmes im Kampf gegen die Technik. Eugen Hodyl half immer mit Dämpfer, Schredder und Töpfen aus. Danke auch an die „Gute Fee“ und Seele der Abteilung: Dorothea Mennerich: „Danke, Doro!“ 


\section{Curriculum vitae}

Geboren am 26.05.1983 in Itzehoe

2002 Abitur an der Kaiser-Karl-Schule in Itzehoe

2002 - 2008 Biologiestudium

Georg-August-Universität in Göttingen

Abschluss: Diplom-Biologin (Note: sehr gut)

Thema der Diplomarbeit

„Quantifizierung von Getreideblattlaus-Parasitoid-Hyperparasitoid Interaktionen entlang eines Gradienten der Landschaftsdiversität.“

Mündliche Diplomprüfung

Hauptfach: Zoologie

Nebenfächer: Botanik, Naturschutz

Seit 2009 Promotionsstudiengang in Agrarwissenschaften am Institut für

Pflanzenpathologie und Pflanzenschutz an der Georg-August-Universität Göttingen. 


\section{Publications}

\section{Articles}

Wilstermann A, Vidal S (2013) Western corn rootworm egg hatch and larval development under constant and varying temperatures. Journal of Pest Science, DOI 10.1007/s10340-013-0496-8

The final publication is available at link.springer.com

Wilstermann A, Vidal S (2013) Larval development of western corn rootworm populations from European locations and the US differ when exposed to specific temperature regimes. In preparation for submission

\section{Presentations at conferences}

Wilstermann A, Vidal S (2010) Auswirkungen des Klimawandels auf den Schlupf und die Larvalentwicklung des Westlichen Maiswurzelbohrers (Diabrotica virgifera virgifera LeConte) in Norddeutschland. 57. Deutsche Pflanzenschutztagung vom 06. bis 09. September 2010 in Berlin, Vortrag gehalten. Abstract: Julius-Kühn-Archiv 428, pp. 187-188.

Wilstermann A, Vidal S (2011) Climate change impact on Western Corn Rootworm (Diabrotica virgifera virgifera LeConte) hatching and larval development in Northern Germany. DGaaE-Tagung vom 21. bis 24. März 2011 in Berlin, Vortrag gehalten. Abstract: Tagungsband DGaaE 2011, p. 62.

Wilstermann A, Vidal S (2011) Western Corn Rootworm (Diabrotica virgifera virgifera LeConte) development under constant and varying temperature regimes. 24. IWGOKonferenz vom 24, bis 26 Oktober in Freiburg, Poster präsentiert. Abstract: Tagungsband 24th IWGO Conference \& 3rd International Conference of Diabrotica Genetics, Poster 22. 


\section{Eidesstattliche Erklärung}

Hiermit erkläre ich eidesstattlich, dass diese Dissertation selbständig und ohne unerlaubte Hilfe angefertigt wurde.

Göttingen, März 2012 